\title{
Predictability of Growth in Emerging Markets: Information in Financial Aggregates
}

Banegas, Ayelen
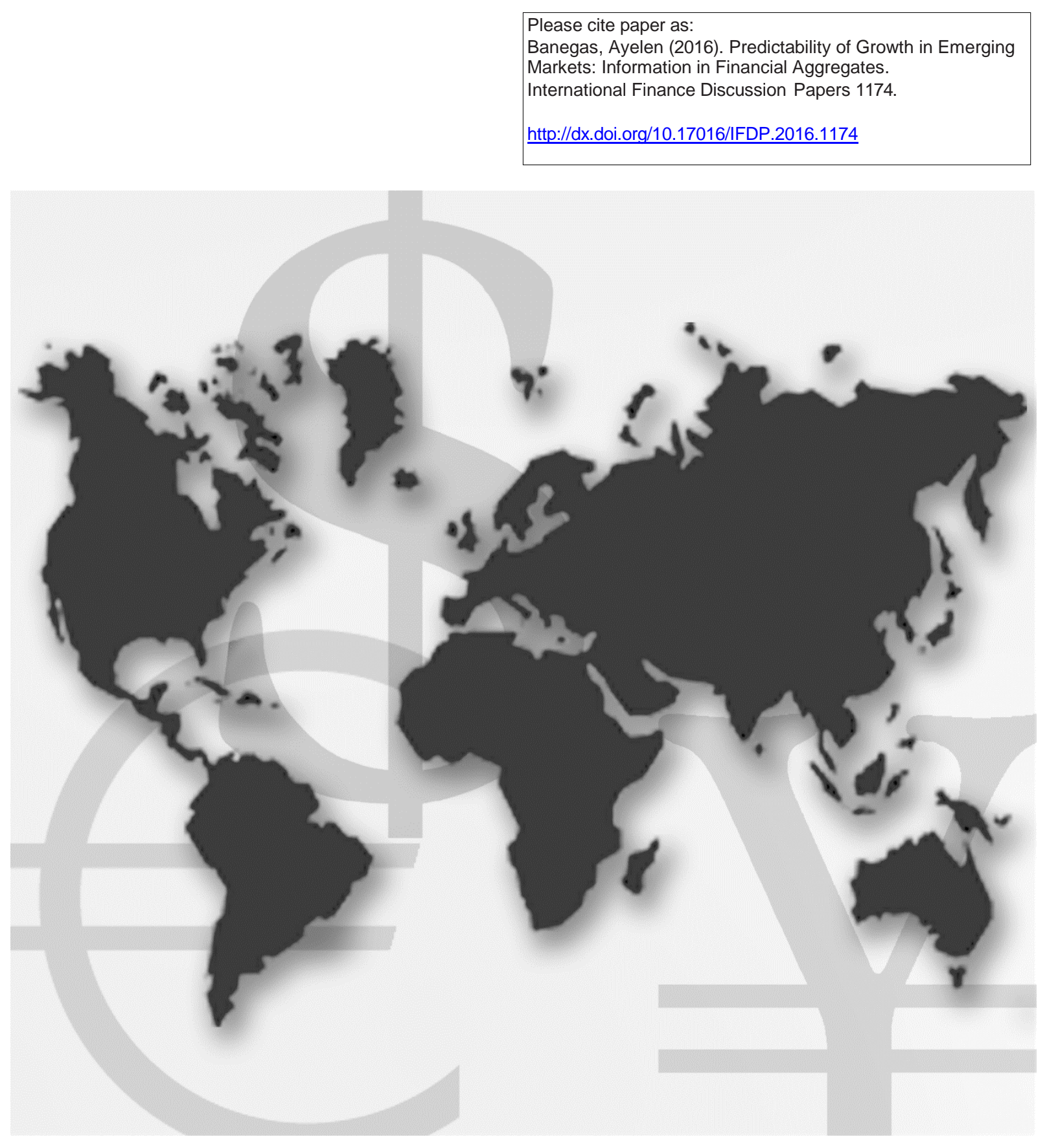

\section{International Finance Discussion Papers}

Board of Governors of the Federal Reserve System

Number 1174

July 2016 
Board of Governors of the Federal Reserve System

\author{
International Finance Discussion Papers \\ Number 1174
}

July 2016

Predictability of Growth in Emerging Markets: Information in Financial Aggregates

\author{
Ayelen Banegas
}

NOTE: International Finance and Discussion Papers are preliminary materials circulated to stimulate discussion and critical comment. References in publications to International Finance Discussion Papers (other than an acknowledgment that the writer has had access to unpublished material) should be cleared with the author or authors. Recent IDFPs are available on the Web at www.federalreserve.gov/pubs/ifdp/. This paper can be downloaded without charge from Social Science Research Network electronic library at www.ssrn.com.

The views expressed in this paper are solely the responsibility of the author and should not be interpreted as reflecting the views of the Board of Governors of the Federal Reserve System. 


\title{
Ayelen Banegas* \\ Federal Reserve Board
}

July 2016

\begin{abstract}
This paper tests for predictability of output growth in a panel of 22 emerging market economies. We use pooled panel data methods that control for endogeneity and persistence in the predictor variables to test the predictive power of a large set of financial aggregates. Results show that stock returns, the term spread, default spreads and portfolio investment flows help predict output growth in emerging markets. We also find evidence that suggests that global aggregates such as the performance of commodity markets, a cross-sectional firm size factor, and returns on the market portfolio contain information about the future state of the economy. We benchmark our results against those from the U.S. and find that there are differences in the ability of financial markets in predicting economic growth. Our results generalize to emerging markets previous findings in the empirical macro-finance literature on the linkages between financial market performance and the real economy.
\end{abstract}

JEL Classification: E44, G15

Keywords: Output growth predictability, emerging markets, leading indicators, financial variables

${ }^{*}$ Federal Reserve Board, Division of Monetary Affairs. Washington, D.C. 20551. Tel.: +1 2024523767 . Maria.A.Banegas@frb.gov 


\section{Introduction}

The recent financial crisis triggered a revival of the empirical and theoretical macro-finance literature on the links between financial markets and the real economy. Among the questions that have been at the center of the debate is whether we could have predicted the crisis. As a result, in recent years, the debate on leading indicators as predictors of future economic activity has reemerged. ${ }^{1}$ Although much of the earlier empirical macro-finance literature on output growth predictability focuses on developed countries (i.e.Harvey (1988); Estrella and Hardouvelis (1991); Weber (1998); Estrella and Mishkin (1998); Hamilton and Kim (2002); Stock and Watson (1989, 2003); and Gilchrist, Yankov, and Zakrajsek (2009)); not much work studies the predictive relationship between financial markets and output growth in emerging markets. ${ }^{2}$ This is an important under-explored area of research as emerging markets have become a central player in the global economy. 3

In this paper, we contribute to the empirical macro-finance literature by studying the predictive dynamics of economic growth and evaluating the extent to which financial aggregates can be used as leading indicators of economic growth in emerging markets, without taking a stand on whether our finding indicate a causal relation or whether they reflect information in forward-looking financial aggregates. Specifically, we test whether stock returns, capital flows, interest rates, valuation measures, commodity prices, and a set of well-established risk factors, among other variables, contain information about the future state of the economy. To address our question, we construct a dataset for 22 emerging market countries that were selected based on Standard and Poor's classification system. Our sample includes a large set of country-specific and global macroeconomic and financial variables, such as real GDP growth, interest rates, capital flows, valuation measures,

\footnotetext{
${ }^{1}$ In particular, there is a large body of work on early warning indicators. See Frankel and Saravelos (2012) for a detailed literature review.

${ }^{2}$ Mauro (2003) focuses on the correlation of lagged stock returns and output growth in emerging markets and finds evidence of a positive relationship in several countries.

${ }^{3}$ Over the past few years we have seen emerging markets outperforming and recovering faster from the recent crisis than developed economies. Many of the more succesful countries have undertaken economic and political reforms in the pre-crisis period that resulted in more favorable business conditions and stronger government balance sheets. These reforms included, but were not limited to, fiscal programs aimed at controlling public deficits, trade agreements, financial system regulations and monetary policy that led to lower inflation rates.
} 
and commodity indices, covering the period from 1992 to $2010 .{ }^{4}$ To test for predictability of output growth we use pooled panel data methods that control for endogenous and persistent predictor variables. An extensive amount of literature documents the effects of endogeneity and persistence on time-series predictive regressions. Stambaugh (1999) shows that OLS estimates are biased in the presence of endogenous and persistent regressors, inhibiting normal inference. Hjalmarsson (2010) finds that these econometric issues also apply to panel data forecasting models when fixed effects are included and proposes a robust estimator that corrects for the Stambaugh-bias. Even though Stambaugh-bias has been discussed exclusively in the return predictability literature, we find that it can also arise in the context of output growth predictability. In particular, valuation ratios such as the dividend yield and the price-earnings ratio, as well as the market capitalization ratio, prove to be highly persistent and endogenous. For this reason, we follow Hjalmarsson's methodology to correct for these features when testing for output growth predictability. Moreover, as part of our empirical analysis, we test for predictability at different forecasting horizons by applying reverse regression methods proposed by Hodrick (1992) and extended by Wei and Wright (2010).

Our results show that stock returns, capital flows, default spreads, the term spread, and returns on commodity prices can help predict output growth in emerging market economies. In particular, large capital inflows predict subsequent high GDP growth as does a high term spread. Conversely, higher default spreads on emerging market government debt signals lower future GDP growth. Our findings also suggest that some variables such as the term spread, stock returns, and capital flows contained higher predictive power during the '90s, while the short interest rate and portfolio flows prove more useful during the past decade. Furthermore, for regional-level panels, we find that Latin America exhibits the strongest evidence of output growth predictability across regions.

We also extend previous findings on the links between output growth and Fama and French (1993) risk factors (i.e. Liew and Vassalou (2000)). In particular, we test whether book-to-market, size, and the market portfolio contain information about the future state of the economy. We find strong evidence of the predictive power of the size factor and returns on the market portfolio to be consistent with small firms being more sensitive to the business cycle than large firms (see, for example, Perez-Quiros and Timmermann (2001)).

We compare our results with empirical findings in the US. Given the characteristics of emerging market economic, financial, and institutional systems, we can expect the transmission channels

\footnotetext{
${ }^{4}$ We selected the period under analysis based on data quality restrictions.
} 
between financial markets and the real economy to work differently because of liquidity or credit market frictions, among other factors, in emerging markets. Overall, we find that there are differences in the ability of financial markets to predict future output growth. Variables that prove to convey information about the future state of the economy in developing countries, such as the term spread, stock returns, and commodity prices, lack any predictive power in the context of the US. Further, while we find a positive relationship between capital and portfolio flow ratios and future output in these transitional economies, results for the US suggest that increases in these ratios are followed by subsequent declines in GDP growth. These findings can be interpreted as a flight to quality effect where in periods of global turmoil investors move their capital away from riskier investments to apparently safer allocations in developed markets.

In summary, by identifying a set of financial aggregates that convey information about future output growth, our analysis sheds some light on the relationship between financial markets performance and the state of the economy in developing economies. These findings can be useful to policymakers and market participants who try to understand and predict the business cycles of emerging markets.

The paper is organized as follows: section 2 details the predictive regression methodology, section 3 describes our data set, section 4 presents our empirical findings, section 5 provides robustness analysis and section 6 presents conclusions.

\section{Estimation}

An extensive amount of literature documents the effects of endogeneity and persistence on timeseries predictive regressions. Stambaugh (1999) shows that OLS estimates are biased in the presence of endogenous and persistent regressors, inhibiting normal inference. Hjalmarsson (2010) finds that these econometric issues also apply to panel data forecasting models when fixed effects are included and proposes a robust estimator that corrects for the Stambaugh-bias. Even though Stambaughbias has been discussed exclusively in the return predictability literature, as shown in tables 2 and 3 , we find that it can also arise in the context of output growth predictability. In particular, there is evidence of high persistence and endogeneity when using the capitalization ratio, the dividend yield and the price earning ratio as regressors. Also, the term spread and short interest rate are 
highly persistent. However, cross-correlations for these predictors lack statistical significance in most of the countries.

For this reason, we follow Hjalmarsson's methodology to correct for these features when testing for output growth predictability. Our panel data framework is represented by the following system of equations:

$$
\begin{gathered}
y_{i, t}=\alpha_{i}+\beta^{\prime} x_{i, t-1}+u_{i, t} \\
x_{i, t}=A_{i} x_{i, t-1}+v_{i, t} \\
A_{i}=I+C_{i} / T
\end{gathered}
$$

where $y_{i, t}$ is the real GDP growth for country $i$ at time $t, x_{i, t}$ is an $m \times 1$ vector of predictor variables, $u_{i, t}$ are country-specific innovations assumed to be martingale difference sequences with finite fourth moments, $A_{i}$ is an $m \times m$ matrix representing the near unit root assumption and $C_{i}$ is the local-tounity parameter. The model allows for endogeneity by letting $u_{i, t}$ and $v_{i, t}$ be contemporaneously correlated and introduces persistency by defining the dependent variable, $x_{i, t}$, as an autoregressive process of order 1 with roots being local to unity. By letting $C_{i}$ differ across countries, we allow for the time series to have different persistence levels. We find this property to be of relevance in our analysis because we are considering a heterogenous panel of countries, and can therefore expect regressors to have different cross-sectional characteristics. ${ }^{5}$

Using panel data methodology results in more precise estimates than the analogous individual time-series regressions. Furthermore, even in the case where the slope coefficients differ across countries, the pooled estimator will provide information about the average slope coefficient. Also, pooling the data allows us to evaluate whether our group of developing countries possesses common characteristics. This methodology is of particular relevance to investors who consider investing in emerging markets as an asset class, rather than in individual stocks. For example, investors gaining exposure to global emerging markets through mutual fund investing.

In our baseline setting we consider three different scenarios for pooled estimation presented in Hjalmarsson's (2010) study. First, the naive case where we estimate a standard pooled estimator.

\footnotetext{
${ }^{5}$ The near unit root assumption is preferred to a unit root set up because it is a less restrictive condition on the regressors when modelling non-stationary series. Also, as Hjalmarsson (2010) points out, under the near unit root assumption the degree of persistence in the predictive regressors will be carried over to the asymptotic distribution. This allows the small sample distribution to correspond with that predicted by asymptotic distribution theory.
} 
We then allow for the possibility of individual effects by letting $\alpha_{i}$ differ across countries. Finally, we consider a recursively demeaned estimator that corrects for the bias found in the fixed effects procedure.

The standard pooled estimator does not allow for individual effects and is given by the following equation:

$$
\begin{gathered}
\hat{\beta}_{\text {Pool }}=\left(\sum_{i=1}^{n} \sum_{t=1}^{T} \tilde{x}_{i, t-1} \tilde{x}_{i, t-1}^{\prime}\right)^{-1}\left(\sum_{i=1}^{n} \sum_{t=1}^{T} \tilde{y}_{i, t} \tilde{x}_{i, t-1}\right) \\
\tilde{y}_{i, t}=y_{i, t}-\frac{1}{n T} \sum_{i=1}^{n} \sum_{t=1}^{T} y_{i, t} \\
\tilde{x}_{i, t}=x_{i, t}-\frac{1}{n T} \sum_{i=1}^{n} \sum_{t=1}^{T} x_{i, t}
\end{gathered}
$$

Despite the fact that from an economic perspective we might think that country-specific intercepts should be considered, it is worth evaluating this simple case because of the econometric properties of this estimator. In particular, this estimator is asymptotically normally distributed therefore allowing for normal inference.

The fixed effects estimator is defined by the following equation:

$$
\begin{gathered}
\hat{\beta}_{F E}=\left(\sum_{i=1}^{n} \sum_{t=1}^{T} \underline{x}_{i, t-1} \underline{x}_{i, t-1}^{\prime}\right)^{-1}\left(\sum_{i=1}^{n} \sum_{t=1}^{T} \underline{y}_{i, t} \underline{x}_{i, t-1}\right) \\
\underline{y}_{i, t}=y_{i, t}-\frac{1}{T} \sum_{t=1}^{T} y_{i, t} \\
\underline{x}_{i, t}=x_{i, t}-\frac{1}{T} \sum_{t=1}^{T} x_{i, t-1}
\end{gathered}
$$

Although economically more meaningful in the context of emerging markets, this estimator suffers from a second-order bias in the presence of endogenous regressors. The time-series demeaned regressor, $\underline{x}_{i, t-1}$, incorporates information corresponding to periods after $t-1$. As a result the demeaned regressor is correlated with $u_{i, t}$, generating a small sample bias. ${ }^{6}$ This bias, also known as the Stambaugh bias (Stambaugh (1999)), can be defined in terms of the limiting bias in the

\footnotetext{
${ }^{6}$ In the standard pooled estimation, the small sample bias is not an issue since the effects of endogeneity are eliminated when pooling the data.
} 
autoregressive root of the predictor variable. As shown in Hjalmarsson (2007), the analogue of the Stambaugh bias in the panel case can be written as

$$
\underset{(T, n \rightarrow \infty)_{s e q}}{p l i m} T\left(\hat{\beta}_{F E}-\beta\right)=\underset{(T, n \rightarrow \infty)_{s e q}}{p l i m} \frac{w_{12}}{w_{22}} T\left(\hat{\rho}_{F E}-\rho\right)
$$

where $w_{12}$ and $w_{22}$ are the average covariance between $u_{i, t}$ and $v_{i, t}$ and variance of $v_{i, t}$ respectively, and $\hat{\rho}_{F E}$ is the fixed effects estimator of the autoregressive root of the predictor variable. ${ }^{7}$

The recursively demeaned estimator that corrects for this bias is given by the following equation:

$$
\begin{gathered}
\hat{\beta}_{F D}=\left(\sum_{i=1}^{n} \sum_{t=1}^{T} \underline{x}_{i, t-1}^{d d} x_{i, t-1}^{\prime}\right)^{-1}\left(\sum_{i=1}^{n} \sum_{t=1}^{T} \underline{y}_{i, t}^{d d} x_{i, t-1}\right) \\
\underline{y}_{i, t}^{d d}=y_{i, t}-\frac{1}{T-t+1} \sum_{s=t}^{T} y_{i, s} \\
\underline{x}_{i, t}^{d d}=x_{i, t}-\frac{1}{T-t+1} \sum_{s=t}^{T} x_{i, s}
\end{gathered}
$$

This estimator uses $x_{i, t-1}$ as an instrument and $\underline{u}_{i, t}^{d d}$ includes only data corresponding to periods after $t$. Therefore, by forward demeaning, $\underline{u}_{i, t}^{d d}$ is independent of $x_{i, t-1}$ and no second-order bias arises. $^{8}$

Many studies have shown that the predictive power of a variable may depend on the forecasting horizon under analysis. Variables that proved to be helpful predictors for short horizons may lack any predictive power when tested over longer horizons, and vice-versa. Hence, as part of our empirical analysis, we test for predictability of our set of financial aggregates using different horizons. In doing so, we use reverse regressions as proposed by Hodrick (1992) who shows that, under the null of no predictability and covariance stationary, in the usual long horizon predictive regression

$$
\Delta y_{t: t+k}=\alpha_{k, 1}+\beta_{k, 1} x_{t}+u_{t: t+k}
$$

with $k$ representing the number of periods ahead considered in the forecast, and $\Delta y_{t: t+k}=$ $\Delta \log \left(y_{t+k} / y_{t}\right)=\Delta y_{t: t+1}+\Delta y_{t+1: t+2}+\ldots+\Delta y_{t+k-1: t+k}$ the $k$-period GDP growth, the numerator

\footnotetext{
${ }^{7}$ Note that when the local-to-unity parameters are unknown, direct estimation of the bias is not feasible.

${ }^{8}$ See Hjalmarsson (2010) for theorems and proofs of the properties of the above estimators.
} 
of the slope coefficient estimated by

$$
\operatorname{cov}\left[\left(\Delta y_{t: t+1}+\ldots+\Delta y_{t+k-1: t+k}\right) ; x_{t}\right]
$$

is equivalent to

$$
\operatorname{cov}\left[\Delta y_{t: t+1} ;\left(x_{t}+\ldots+x_{t-k+1}\right)\right]
$$

where (8) is the numerator of the slope coefficient in the following predictive regression

$$
\Delta y_{t: t+1}=\alpha_{k, 1}+\gamma_{k, 1} x_{t-k+1: t}+u_{t: t+1}
$$

with $x_{t-k+1: t}=x_{t}+\ldots+x_{t-k+1}$. The coefficient in the forward regression, $\beta_{k}$, can be expressed as a linear function of the coefficient in the reverse regression, $\gamma_{k}$

$$
\beta_{k}=\frac{\tilde{V}_{x x}}{V_{x x}} \gamma_{k}
$$

where $\tilde{V}_{x x}$ and $V_{x x}$ are the covariance matrices of the regressors in the reverse and forward regressions respectively. As a result, testing the null of no predictability $\beta_{k, 1}=0$ is equivalent to testing $\gamma_{k, 1}=0$. However, under the reverse regression setting of equation (9), inference will lead to less size distortions. Recent work by Wei and Wright (2010) extends these findings by considering persistency in the predictive regressors. They model the predictors as autoregressive processes of order 1 with near unit roots and find that reverse regression methods can still be performed in the context of nearly non-stationary processes. Furthermore, their results confirm previous findings that inference is more robust in small samples under the reverse regressions than with typical long horizon regression methods (i.e., equation (6)). We use this methodology to perform inference for long-term horizon growth rates by regressing the one-period ahead return on the sum of the regressors over the past $\mathrm{k}=4$, and $\mathrm{k}=8$ periods.

\section{Data}

Our study focuses on twenty-two countries that were classified as emerging market economies by Standard and Poor's as of December 2009. We develop a comprehensive dataset of country-specific and global macroeconomic and financial variables from December 1992 to March 2010. We use quarterly series that include real GDP growth rates, inflation, stock returns, valuation measures, 
interest rates, capital flows, and commodity returns. GDP series are from the International Monetary Fund's International Financial Statistics (IFS) database except in the cases of Mexico, Taiwan, and South Africa where the source is Global Financial database (GFD). We deflated these series using the corresponding GDP deflators from the IFS database. We tested and removed seasonality using the X-12-ARIMA Seasonal Adjustment Program from the U.S. Census Bureau. Table 1 presents descriptive statistics for the GDP growth series for the fourth quarter of 1992 to the first quarter of 2010. During the span of our sample all countries report positive average output growth rates. On average, quarterly GDP rates reach $1.13 \%$, with China exhibiting the highest average growth rate $(3.05 \%)$ and Mexico the lowest $(0.61 \%)$ within emerging markets. ${ }^{9}$ In terms of volatility, Morocco presents the highest average volatility level (4.2\%) while Hungary shows the most stable growth pattern $(1.05 \%)$.

Stock market index returns for our set of countries are from the Global Financial Database. They are inflation adjusted, include both changes in price and dividends, and are expressed in local currency terms. With respect to valuation measures, we consider country-specific dividend yields and price-earning ratios from GFD. These aggregates are based on large cap stocks which represent about $75 \%$ of the capitalization of the country. We also study the information content of stock market capitalization on subsequent output growth. In doing so, we employ capitalization growth rates and a ratio of capitalization to GDP from GFD.

We evaluate different measures of financial flows from the balance of payments in our panel of developing countries. At the broader level, we consider capital and portfolio flows. Capital flows are the net sum of direct investment, portfolio investment, financial derivatives, and other investments from the financial account. Portfolio investment flows are a subset of the capital flow variable and account for transactions with nonresidents in financial securities. We disaggregate this category into debt and equity flows. Debt flows are the net sum of both inflows and outflows of assets and liabilities covering fixed income instruments such as bonds and money market securities. Equity securities are the sum of assets and liabilities covering stocks, and similar instruments that represent ownership of equity. Within capital flows, we also evaluate the predictive power of direct investment capital flows. This aggregate is the sum of direct investment abroad and direct investment in the reporting country. The source of our flow aggregates is the IFS database.

Our interest rate variables are from GFD. We consider the term spread, the real short interest

\footnotetext{
${ }^{9}$ The number of observations for GDP series vary across countries.
} 
rate, and returns on JPMorgan's Emerging Markets Bond Index Plus country indices (EMBI+). This family of indices reports the spread between local and US government debt instruments. More specifically, they track the spread between the average yield on the securities of the local country against that of US treasuries. The local debt instruments include US-dollar denominated Brady bonds, eurobonds and traded loans issued by sovereign entities. We also test whether US interest rate aggregates lead the business cycle of emerging market countries. In doing so, we consider the US default spread, short interest rate and term spread. The default spread is measured as the difference between Moody's Corporate BAA and AAA bond yields, the short interest rate is the yield on the 3-month Treasury Bill, and the term spread is the difference between the yield on the 10-year Government Bond and the 3-month Treasury Bill.

We also consider the performance of a set of commodity indices. We use the Goldman Sachs commodity index (GSCI) as a proxy for the performance of commodity markets at the aggregate level. GSCI is a composite index of commodity sector returns weighted by world production. We also drill down to the sector level and include returns covering agricultural, energy, livestock and precious metal commodity markets from the S\&P GSCI family indices.

Finally, we build and test the predictive power of proxies for Fama and French risk factors. The size factor is the spread between returns on the MSCI Emerging Markets Small Cap and the MSCI Emerging Markets Large Cap total return indices. The book-to-market factor is represented by the return difference between the MSCI Emerging Markets Standard Growth and the MSCI Emerging Markets Standard Value total return indices. Lastly, we use the MSCI Emerging Markets total return index as a proxy for the market portfolio.

\section{Empirical Results}

This section presents the empirical findings for our set of predictive regressions. Tables 4 through 8 introduce our baseline pooled and time series results for the set of return and valuation measures, interest rates and flows. The pooled regressions test the predictive power of country-specific financial aggregates to forecast subsequent, one-year-ahead, and two-year-ahead output growth. ${ }^{10}$ Following the empirical macro-finance literature (i.e.,Stock and Watson (2003)), we include lagged

\footnotetext{
${ }^{10}$ Note that, by construction, out-of-sample excercises are not feasable the forward demeaning estimator.
} 
GDP growth and the variable of interest as regressors. However, for convenience, we report results only for our set of financial predictors. ${ }^{11}$ We also normalized our series to allow for comparison across variables. In tables 9 through 12, we shift our focus away from country-specific regressors and assess the forecasting ability of a group of global aggregates. This set of variables includes returns on commodity markets, US interest rates and Fama and French (1993) risk factors. Finally, we also evaluate the differences and similarities on the role of capital markets to predict future economic growth in emerging markets and in the US. In doing so, we test for output growth predictability in the US over the same sample period and use analogous predictive regressors of our emerging market analysis. These results are described in table 13.

\subsection{Returns and Valuation Measures}

Although the goal of this paper is not to establish causality in the traditional economic sense, our results can be related to financial theories that relate stock prices to the present value of future cash-flows. In particular, theories such as the "passive informant" hypothesis suggests that positive news about future output growth will be translated into higher equity market prices, resulting in a positive relationship between stock returns and future GDP growth. Empirical evidence on the predictive power of stock returns is mixed. An early study by Harvey (1989) finds that about only $5 \%$ of variation in output growth is explained by stock market related variables in the US over the 1953-1989 period. On the other hand, Estrella and Mishkin (1998) find evidence that stock price indexes are good predictors of US recessions. Specific to emerging markets, Mauro (2003) focuses on the correlation of lagged stock returns and output growth and finds this relationship to be positive and significant in several countries. Moreover, his findings suggest that countries with a high market capitalization to GDP ratio exhibit stronger correlations. ${ }^{12}$ Although there is no consensus about the empirical success of equity prices and related variables to predict future economic activity, they are widely considered by policy makers and investors.

In our baseline case, we find strong evidence of the predictive power of stock market returns in

\footnotetext{
${ }^{11}$ Details are available upon request.

${ }^{12}$ There is also a relatively new literature that studies stock return predictability in emerging markets. Harvey $(1995,1994)$ shows that equity returns are predictable in some developing countries when conditioning on country specific and global information variables such as dividend yields, past returns, currency index and earning-price ratio. Bekaert, Harvey, and Lundblad (2007) find that local market liquidity is an important driver of returns in these economies.
} 
emerging markets. As presented in table 4, the slope coefficients are statistically significant across models, suggesting that returns are positively related to future output growth. Furthermore, when we look at longer forecasting horizons our results are validated. Both panels $\mathrm{B}$ and $\mathrm{C}$ show that there is information content in equity market returns at the one- and two-year horizons. Strongest results are for the one year ahead forecasts. ${ }^{13}$ Time series regressions in table 5 point in the same direction. However, only ten of the countries present statistically significant coefficients.

We also evaluate the predictive relationship between market capitalization, commonly used as an indicator of stock market development, and GDP growth. In doing so, we consider a ratio that relates capitalization to GDP. Results from our pooled estimations in table 4 lack statistical significance when forecasting one quarter and two-year-ahead economic activity. Only the slope coefficient for our capitalization ratio is significant under the fixed effects model at the one-yearahead horizon. This result suggests a negative predictive relationship. However, as shown in tables 2 and 3, this variable is both highly persistent and endogenous. As a result, our fixed effects estimator is biased. ${ }^{14}$ Therefore, we focus on the forward demeaned estimator that corrects for this small sample bias. Our country level results present no clear pattern about the relationship between capitalization and subsequent output growth. As table 5 shows, slope coefficients lack statistical significance in most of the countries. Estimates are significant only in Argentina, Egypt, and Malaysia, where we find a positive relationship between capitalization and subsequent output growth.

Two widely tested valuation measures in the return predictability literature are the price-earning ratio and the dividend yield. As shown in tables 2 and 3, we find that both aggregates suffer from a second order bias. We correct for this bias in our demeaned estimation. As presented in table 4, panels A through $\mathrm{C}$, we find no evidence of the predictive power in the price-earning ratio. Only the fixed effects estimator is statistically significant when forecasting two years ahead. However, when we correct for the Stambaugh bias, we fail to reject the null of no predictability. ${ }^{15}$ Time series regressions in table 5 provide no clear pattern of the predictive power of $\mathrm{P} / \mathrm{E}$ ratios. Similarly,

\footnotetext{
${ }^{13}$ Lagged GDP growth included in these bivariate regressions lack statistical significance at any forecasting horizon and under all model specifications.

${ }^{14}$ Note that since the direction of the bias depends on the sign of the cross-correlations of the innovation processes, and in this case $\operatorname{cov}\left(u_{i}, v_{i}\right)>0$, the bias is negative and therefore we see $\beta_{F D}>\beta_{F E}$.

${ }^{15}$ Lagged GDP coefficients are positive and statistically significant across model specifications and horizons. These results are available upon request.
} 
we find no predictive relationship between lagged dividend yields and future output growth in our robust estimations. Both the standard pooled and the fixed effects coefficients suggest evidence of a negative predictive relationship between these aggregates when forecasting one quarter ahead ( see panel A of table 4). However, when we allow for individual effects and correct for endogeneity and persistence, signs of predictability disappear. This result is of particular relevance in the context of a highly persistent variable such as the dividend yield, since findings from our fixed effects estimation could result in misleading interpretations. ${ }^{16}$ Time series regressions in table 5 lack statistical significance in a large number of countries. However, when significant, results suggest a negative predictive relationship between dividend yields and subsequent output growth.

When we compare the results of emerging markets and from the United States (table 13), we find similar patterns for capitalization and the dividend yield. In particular, there is no sign of predictability in these two measures; slope coefficients lack statistical significance when forecasting one-quarter-ahead GDP growth. On the other hand, we find that stock market returns, which lead economic growth in emerging markets, have no predictive power in the context of the US. Also, the price-earning ratio, which presents no evidence of predictive power in emerging markets, can be a helpful predictor of subsequent GDP in the US. Finally, although there are differences in the information content of valuation measures across markets, we find some similarities in the characteristics of the data. Specifically, aggregates that show high levels of persistence and cross-correlations in emerging markets present the same patterns in the US. This is the case for capitalization ratio, the dividend yield, and the price-earning ratio.

\subsection{Interest Rates}

Table 4 presents results for the real short interest rate, term spread and default spread. As panels A through $\mathrm{C}$ show, we find strong evidence of predictability in the spreads when predicting future GDP growth. In particular, higher default spreads on emerging market government debt signal lower output growth. ${ }^{17}$ This counter-cyclical predictive relationship is supported by literature on credit channels linking the financial and real side of the economy, where worsening in the quality

\footnotetext{
${ }^{16}$ In this bivariate setting, lagged GDP coefficients are both positive and statistically significant.

${ }^{17}$ Arellano and Mendoza (2002) document that episodes of sudden stops in emerging markets are characterized by sharp and unexpected declines in EMBI+ spread indices (our measure of default spreads) and plummeting equity markets.
} 
of government balance sheets are translated into higher default risk, resulting in higher borrowing rates. These tighter financial conditions negatively impact future economic growth.

Conversely, a high term spread predicts a future increase in GDP growth (i.e., short interest rate declines relative to the longer rate are followed by future rises in economic activity). Estimates are both positive and statistically significant across models when forecasting subsequent and oneyear-ahead output growth. This predictive relationship can be explained in terms of an expectation and a term premium effect. In the first case, spreads are expected to convey information about future short rates. The positive predictive relationship is based on the expectations hypothesis of the term spread and the impact of monetary policy. For example, easing of monetary policy is expected to positively impact interest sensitive sectors, boosting economic activity. On the other hand, the term premium effect signals changes in the term premium related to the compensation demanded for holding long bonds, influenced by risk and liquidity premium among other factors. ${ }^{18}$ Overall, our results are in line with a large body of research that finds that the term spread can be a useful predictor of future GDP growth in developed markets. For example, Estrella and Hardouvelis (1991) find evidence that the slope of the yield curve can predict changes in real output. Harvey (1988) documents that the expected real term structure forecasts consumption growth. ${ }^{19}$

Regarding the real short interest rate, by adding lagged GDP into the regression, the information content of this aggregate vanishes. Our estimates lose predictive power across models and horizons. $^{20}$

Time series regressions, as shown in table 6, lack statistical significance for most of our emerging market countries. Nevertheless, when they are significant, the real short term rate and default spread signal a negative relationship with future GDP growth. These findings do not extend to the term spread where there is no clear pattern in the country level estimates.

Our empirical results also suggest that there are some differences in the role of interest rates

\footnotetext{
${ }^{18}$ Hamilton and Kim (2002) decompose the contribution of the term spread into the expected changes in interest rates and the term premium and find that both factors are relevant for forecasting real GDP growth in the US.

${ }^{19}$ See Stock and Watson (2003) for a literature review.

${ }^{20} \mathrm{~A}$ strand of the macro-literature looks at the relationship between the real interest rates emerging economies face in international markets and the business cycle. Fernndez-Villaverde, Guerron-Quintana, Rubio-Ramirez, and Uribe (2011) build real interest rates on loans denominated in US dollars as the sum of an international rate and a country risk spread and find that, increases in interest rates volatility have a negative effect on output growth. Previous work by Neumeyer and Perri (2005) finds that real rates are countercyclical and lead the business cycle of a group of small open developing economies.
} 
in predicting output growth in the US and emerging markets. In particular, the term spread that proved to be a helpful predictor in emerging markets shows no predictive power in the US over our sample period. ${ }^{21}$ On the other hand, the default spread and the real short interest rate present similar patterns across markets. ${ }^{22}$

\subsection{Flows}

Historically, we have seen capital flight from developed countries into emerging markets seeking investment opportunities with higher expected returns. These inflows boosted economic growth, relaxed liquidity constraints, raised asset prices and broadened and increased the depth of many of these financial markets. On the negative side, capital outflows have preceded financial and economic crisis in emerging markets. ${ }^{23}$ In this section we use country-level data on net capital flows and its components (i.e. direct and portfolio investment flows) to empirically evaluate the predictive power of capital flows in forecasting GDP growth. Results for our measures of flows are presented in tables 4, 7 and 8 . Table 4 introduces pooled results at the aggregate level, table 7 looks at components of portfolio investment and capital flows and table 8 presents results for time series predictive regressions.

As described in table 4, we find evidence of the predictive power of country flows in forecasting economic activity in emerging markets. Both capital and portfolio flow ratios present statistically significant slope coefficients when we forecast one-quarter-ahead output growth. Results suggest that periods of capital and portfolio inflows anticipate future output growth, and in turn, periods dominated by large outflows are followed by declines in economic activity. Furthermore, these results are extended in table 7 . We find that debt and equity security flows as well as direct investment flows can be useful predictors of future economic growth. Slope coefficients are statistically significant signaling a positive relationship when predicting subsequent growth. Although the causality

\footnotetext{
${ }^{21}$ Work by Haubrich and Dombrosky (1996), Dotsey (1998), and Kucko and Chin (2009) examine the evidence of the yield curve as predictor of future economic activity in the US and find that the predictive power of the yield curve has deteriorated in recent years.

${ }^{22}$ Note that in the case of the default spread we can not perform a precise comparison because we consider corporate bond yield spreads in the US, while in emerging markets we track spreads between local government debt instruments and US treasuries.

${ }^{23}$ There is a large body of research on sudden stops that models the effects of capital flows on output growth in emerging markets, e.g., Calvo (1998), Reinhart and Calvo (2000), Ferretti and Razin (2000), among others.
} 
question is beyond the scope of this paper, the positive predictive relationship of portfolio flows suggests an information and portfolio optimization effect. As investors become optimistic about opportunities in emerging markets, we see financial inflows into local debt and equity securities. Overall, results suggest that investors are well informed and have the ability to react to news and expectations about future economic conditions in emerging markets. Net inflows to equity and debt markets predict subsequent output growth. Conversely, net portfolio outflows signal lower GDP growth. Also, direct investment capital flows present evidence of predictability over subsequent and one-year horizons, signaling a positive relationship between flows and future economic activity. These results can be related to the effect of demand shocks, where an exogenous increase in investments will be associated with a higher demand and a subsequent increase in the level of output.

Our country level results, when statistically significant, support findings for our pooled models. As described in table 8, both capital and portfolio investment flows present highly economically significant slope coefficients signaling a positive relationship between inflows and subsequent economic activity.

When we extend our forecasting window to one and two years, we lose predictability in our aggregate measure of portfolio investment flows. Moreover, if we disaggregate further, we find a similar pattern in the case of debt security flows. On the other hand, fixed effects estimates for equity flows are statistically significant when predicting one-year-ahead GDP growth. We also find a reversal in the predictive relationship between capital flows and GDP when forecasting two years ahead. As seen in many south East Asian and Latin-American countries during the 90's, strong capital inflows in weak financial systems that are unable to absorb flows productively can lead to financial bubbles, capital flow reversals, inflation and higher vulnerability to external shocks, among other unintended outcomes that negatively impact economic growth.

As shown in table 13, results for the US are strikingly different when forecasting one-quarterahead GDP growth. In particular, while we find a positive relationship between capital and portfolio flow ratios and subsequent output growth in emerging markets, our results suggest that in the US, increases in the ratios of flows to GDP are followed by declines in output growth. On the other hand, net capital and portfolio outflows signal subsequent increases in GDP growth. This could be interpreted as a flight to quality effect. In periods of global turmoil, investors will move their capital away from perceived as riskier investments in international markets, to safer allocations in 
the US. ${ }^{24}$

\subsection{Commodities}

It is well known that commodity markets are a vital engine for economic growth in many emerging market countries. Periods of higher prices in international commodity markets are expected to be related to higher output growth, while market declines will negatively impact the growth prospects of many emerging economies. In table 9 , panel A, we investigate the predictive power of commodity market returns at the global and sector level to forecast economic activity. The set of commodity sectors include agriculture, energy, livestock and precious metals. Overall, we find strong evidence of predictability both at the aggregate market level and across sectors. In particular, coefficients for commodity markets are economically and statistically significant across models and horizons at the aggregate level. Nevertheless, the predictive power of commodity market returns appears to be strongest when forecasting subsequent output growth. Given the inelastic nature of demand and supply for commodities, these findings could be interpreted in terms of the effect of demand shocks. As demand for commodities increases, commodity prices rise, having a positive impact on the terms of trade and output of export countries. These results are in line with Chen, Rogoff, and Rossi (2010) who find that commodity prices Granger-cause exchange rates in-sample when regressions are robust to parameter instability. ${ }^{25}$

At the sector level, agricultural and precious metal commodities appear as the most economically significant predictors when forecasting subsequent GDP growth. Also results suggest a positive predictive relationship between energy commodities and future output, with economically and statistically significant coefficients across horizons. However, as we extend the forecasting horizon there is evidence of a decrease in the information content of sector commodity prices with regard to future economic growth. Furthermore, in the two-year forecasts, the livestock sector loses predictability across models.

Findings from our time series regressions validate our pooled results. As described in table 10, slope coefficients of commodity markets are statistically significant in twelve of our countries,

\footnotetext{
${ }^{24}$ Results for the US can also be related to recent work by Bernanke, Bertaut, DeMarco, and Kamin (2011) who argue that capital inflows into the United States, through their effect on assets' yield, likely played a role in the housing bubble and subsequent financial crisis.

${ }^{25}$ They also analyze the reverse predictive relationship and find in- and out-of-sample evidence that exchange rates are robust predictors of commodity prices.
} 
suggesting a positive relationship between lagged returns on commodities and output growth. The only exception is Morocco, which presents a negative slope coefficient. This result does not contradict our findings given the specific characteristics of this country. More than half of their GDP comes from the service sector while the industry sector represents around $30 \%$ of their output. All sector level predictive regressions point in the same direction as the aggregate market. Higher commodity prices are followed by higher economic growth in emerging markets. For example, we find a positive and significant relationship between energy prices and output growth for Russia as well as for other countries.

We compare our results in emerging markets against the United States. As shown in table 13, we find significant differences in the information content of commodity markets. While the performance of global and sector commodity markets convey information about future business conditions in our panel of developing countries, they show no forecasting ability when predicting output growth in the US. Slope coefficients are neither economically nor statistically significant. These results can be related to structural differences between the US and emerging market countries. While in many developing countries, economic growth is heavily dependent on commodities exports, growth in the United States is mostly related to services (around 77\% of its GDP) and to the industry sector to a lesser extent $(22 \%)$. Moreover, extensive literature finds evidence of predictability of energy commodities, such as oil prices in the US (Hamilton, 2003, 2010). However, their results suggest a nonlinear relationship between oil prices and output growth.

\subsection{US Interest Rates}

A large literature finds that the US economy leads the cycle of many developed economies. Traditionally, trade has been considered the most common transmission channel. Periods of growth in the United States would be accompanied by increases in its imports, which in turn would boost economic growth of the trade partner. An extreme example of this direct relationship could be Mexico, whose GDP growth is known to be highly correlated with that of the United States. However, as financial markets become more integrated, they can be expected to be more relevant in the transmission of shocks from the US to the rest of the world.

In this section we also test whether expectations about the US economy that are contained in interest rate aggregates can help predict output growth in emerging countries. As shown in panel $\mathrm{B}$ of table 9, we find evidence that the term and corporate default spreads contain information 
about subsequent GDP growth. In particular, the US term spread has a positive relationship with future growth in emerging markets. Conversely, we find that increases in the US default spread are followed by subsequent declines in output growth. Furthermore, under the pooled and fixed effects settings, the predictive power of the term spread increases as we extend our forecasting horizon to two years. On the other hand, the default spread loses its predictive power as we move to longer term horizons. The short interest rate, represented by the 3-month US treasury bill, shows no signs of predictability in the short term. However, its predictive power emerges when we look at a two years ahead forecasting horizon, where we find economically and statistically significant negative slope coefficients.

As described in table 11, evidence of predictability is limited when we look at individual time series regressions. Results on the term spread lack statistical significance across countries. The US short interest rate helps predict output growth only in the case of China. Finally, the default spread, has a economically and statistically significant negative relationship with growth in only 8 of our 22 countries.

\subsection{Book-to-Market, Size, and The Market Portfolio}

This subsection discusses whether well-known factors such as book-to-market, size, and the market portfolio convey information about the future state of the real economy. As presented in table 12, we find strong evidence of the predictive power of the size factor and market portfolio. Slope coefficients for the size factor are economically and statistically significant across models over the one- and twoyear-ahead forecasting horizons. Positive slope coefficients suggest that outperformance of small over large capitalization stocks precede periods of output growth. Conversely, periods in which small capitalization stocks underperform are followed by declines in future economic activity. As described in table 12, we also find a positive predictive relationship between returns on the market portfolio and future GDP growth. Slope coefficients are statistically significant across horizons, with one-year-ahead forecasts presenting the strongest economic significance. On the other hand, the book-to-market factor shows no evidence of predictive power over one-quarter and one-year horizons. Only when forecasting two years ahead, and in the context of the forward demeaning model, we find a negative relation between book-to-market and future output growth.

These results confirm and extend some previous findings of Liew and Vassalou (2000). Using 
time-series regression analysis and Fama and French risk factors (Fama and French (1993)), Liew and Vassalou (2000) test for output growth predictability in a group of 10 developed markets. They document that the book-to-market, size factor, and market portfolio are positively related to future GDP growth. In the context of emerging markets, we find similarities in the cases of the size factor and market portfolio, where both variables contain information about the future state of the real economy. However, as shown in table 13, while in emerging markets size is positively related with future growth, results suggest a countercyclical relationship in the US during the sample period.

\section{Robustness Analysis}

This section presents a series of additional exercises we perform to evaluate the robustness of our results to different scenarios. First, we allow for global innovations in our data generating process. Second, we split our sample into sub-periods, 1992-1999 and 2000-2010. Third, we test for output growth predictability at the regional level. Fourth, we group our set of countries based on GDP per capita. Fifth, we run our analysis in a multivariate setting. Finally, we perform a cross-validation exercise to check the stability of our results.

As in our baseline scenario, we run bivariate regressions including lagged GDP growth and the variable of interest as regressors. ${ }^{26}$ We also normalized our series by their standard deviation to allow for comparison across variables.

\subsection{Accounting for Common Factors}

We use Hjalmarsson's (2010) framework that in addition to idiosyncratic factors allows for the effect of common shocks to returns and proposes a set of pooled estimators that are robust to cross-sectional dependence. This is of particular relevance when considering the phenomenon of emerging markets because these countries are known to be more vulnerable to external shocks and episodes of contagion than developed countries. As a result, there will be shocks to output growth that will impact emerging markets as a whole while others will be country-specific.

The data generating process accounting for common factors can be described as follows:

$$
y_{i, t}=\alpha_{i}+\beta^{\prime} x_{i, t-1}+u_{i, t}+\delta_{i}^{\prime} f_{t}
$$

\footnotetext{
${ }^{26}$ For convenience we report results only for our set of financial predictors. Results for lagged GDP coefficients are available upon request.
} 


$$
\begin{gathered}
x_{i, t}=A_{i} x_{i, t-1}+v_{i, t}+\Gamma_{i}^{\prime} z_{t} \\
z_{t}=A_{g} z_{i, t-1}+g_{t} \\
A_{g}=I+C_{g} / T
\end{gathered}
$$

where $f_{t}$ represents the common factor in the error term, and $z_{t}$ is the common term in the predictor $x_{i, t} . z_{t}$ is an $\mathrm{AR}(1)$ process with near unit roots defined by $A_{g} \cdot{ }^{27}$

To perform estimation and inference in our panel setting, we use the following estimators that account for common factors:

Robust Pooled Estimation:

$$
\begin{gathered}
\hat{\beta}_{R P}=\left(\sum_{i=1}^{n} X_{i,-1}^{\prime} M_{\bar{H}} X_{i,-1}\right)^{-1}\left(\sum_{i=1}^{n} X_{i,-1}^{\prime} M_{\bar{H}} Y_{i}\right) \\
M_{\bar{H}}=I-\bar{H}\left(\bar{H}^{\prime} \bar{H}\right)^{-1}
\end{gathered}
$$

where $Y_{i}$ is $\mathrm{T} \times 1, X_{i}$ is $\mathrm{T} \times \mathrm{m}$ and $\bar{H}$ is also $\mathrm{T} \times \mathrm{m}$ with $\bar{H}_{t}=\frac{1}{n} \sum_{i=1}^{n} x_{i, t-1}$

Robust Fixed Effects Estimation:

$$
\hat{\beta}_{R F E}=\left(\sum_{i=1}^{n} \underline{\hat{X}}_{i,-1}^{\prime} \underline{\hat{X}}_{i,-1}\right)^{-1}\left(\sum_{i=1}^{n} \underline{\hat{X}}_{i,-1} \underline{\hat{Y}}_{i}\right)
$$

with $\hat{Y}_{i}=M_{\bar{H}} Y_{i}, \hat{X}_{i,-1}=M_{\bar{H}} X_{i,-1}$, and $\underline{\hat{Y}}_{i}$ and $\underline{\hat{X}}_{i,-1}$ being their demeaned versions.

Robust Recursive Demeaning Estimation:

$$
\hat{\beta}_{R R D}=\left(\sum_{i=1}^{n} \hat{X}_{i,-1}^{\prime d d} \hat{X}_{i,-1}\right)^{-1}\left(\sum_{i=1}^{n} \hat{X}_{i,-1}^{\prime} \hat{Y}_{i}^{d d}\right)
$$

where $\hat{Y}_{i}^{d d}$ and $\hat{X}_{i,-1}^{\prime d d}$ are the recursively demeaned versions of $\hat{Y}_{i}$ and $\hat{X}_{i,-1}$.

Table 14 presents results for this setting. As in our baseline case, we run bivariate regressions including lagged GDP and the variable of interest to forecast subsequent GDP growth. ${ }^{28}$ Overall, our baseline results are validated when we allow for common factors. In particular, our set of valuation measures, interest rates and flow aggregates present similar patterns as in table 4 . We

\footnotetext{
${ }^{27}$ All variables defined in the estimation section remained unchanged.

${ }^{28}$ For convenience we only present estimates and t-statistics for our set of country-specific variables. Results for lagged GDP are available upon request.
} 
find a positive predictive relationship between stock returns and subsequent output growth. On the other hand, our measure of capitalization ratio shows no evidence of predictability. Similarly, the dividend yield and price-earnings ratio do not present any predictive power when we allow for individual effects and correct for endogeneity and persistence. We also find that the term spread and real short interest rate convey information about future economic activity. However, under this new setting, the government default spread loses its predictive power. Finally, results for capital and portfolio flows also suggest a strong positive relationship with future economic growth in emerging markets.

\subsection{Sub-sample Analysis}

Our sample encompasses very different market conditions. We cover the financial liberalization process of many developing countries, the Tequila crisis (1995), the Asian crisis (1997), the Ruble crisis (1998), the Tech bubble (1999-2000), the expansion of the European Union (2004), the rise of China and the last global financial and economic crisis, among other key episodes. To gain further insight on the stability of our forecasts, we split our sample into sub-periods. Panels A and B of table 15 present results for the periods 1993-1999 and 2000-2010. Panel C, tests for output growth predictability excluding the period covering the last global crisis,1993-2007.

As shown in panels $\mathrm{A}$ and $\mathrm{B}$, we find that financial aggregates that lead economic growth in our baseline case are validated when we test for predictability in our subsample analysis. In particular, results for stock returns, the term spread, dividend yield and capital flows ratio, among other variables, present some similar patterns in both subsamples. However, there are differences. For example, the real short interest rate, portfolio investment flows and returns on global commodity markets show evidence of predictability only in the last decade, a period of higher economic growth and stronger stock market performance than the 90 's. ${ }^{29}$ At the commodity sector level, results also suggest that energy and livestock commodities convey information about output growth only during the 2000-2010 period. On the other hand, we also find that the price-earnings ratio, an aggregate that lacks predictive power in our baseline scenario, presents evidence of predictability during the

\footnotetext{
${ }^{29}$ During 2000-2010, emerging markets' annual average GDP growth reached 5.7\% while for 1993-1999 GDP growth was $3.7 \%$. Also, average annual returns on emerging equity markets represented by the MSCI Emerging Markets index was $17.6 \%$ for the last decade versus $14 \%$ during the 90 's. In terms of stock market volatility, we find similar volatility levels ( $39.5 \%$ and $40.3 \%$ ) across sub-samples.
} 
90's, signaling a positive relationship with GDP growth. However, predictability vanishes in the last decade when correcting for the small sample bias.

The most striking differences between our subsample and baseline results are related to our set of risk factors. In particular, in our baseline setting estimates for the book-to-market factor lack statistical significance when forecasting subsequent GDP growth. However, when we split our sample into the 90's and 00's we do find evidence of predictability. Results suggest a negative predictive relationship during the 90's while, in line with previous findings in developed countries (Liew and Vassalou (2000)), it becomes positive during the last decade.

Finally, we test for output growth predictability excluding the period covering the last global crisis. As shown in panel C, we find similar patterns as in our baseline results. However, the dividend yield that lacks any predictive power in our baseline case, now shows evidence of predictability even when we correct for the small sample bias. Results suggest a negative predictive relationship with future GDP growth. Also, although the direction of the relationships remains unchanged, we find slight differences in the predictive power of the term spread and commodity returns. The information content of the term spread decreases when we include the period covering the crisis. On the other hand, the predictive power of returns on commodity markets increases when we consider the full sample in our analysis.

\subsection{Regional Analysis}

To gain further insights on the relationship between financial aggregates and future economic activity we split our panel of countries according to their geographic location. Following standard classifications we define three different regions, Asia, Latin America and Europe, Middle East and Africa (EMEA). ${ }^{30}$ We find strong evidence that our set of financial aggregates can be used as leading indicators of economic activity across regions. However, Latin America presents the strongest evidence of output growth predictability. As table 16 shows, results suggest that return and valuation measures such as stock returns and capitalization ratio have the strongest forecasting ability in Latin America. In particular, slope coefficients are larger in this region than in Asia and EMEA. Also, portfolio investment flows measured as a ratio of flows to GDP, although economically

\footnotetext{
${ }^{30}$ Asia comprises China, Indonesia, India, South Korea, Malaysia, Philippines, Taiwan and Thailand. The EMEA region is composed of Czech Republic, Egypt, Hungary, Israel, Morocco, Poland, Russia, South Africa and Turkey. Latin America comprises Argentina, Brazil, Chile, Mexico and Peru.
} 
and statistically significant across regions, present the strongest results in Latin America. As in our baseline case, we find a positive relationship between lagged portfolio flows and GDP growth. Furthermore, interest rate variables such as the short interest rate and the term spread also proved to have higher predictive power in this region than in the rest of the group. On the other hand, we find that the information content about future economic activity of the default spread and capital flows is the strongest in Asia, while returns on global commodity markets appear to play a bigger role in EMEA.

For robustness, we also test for predictability in Asia excluding China, a key driver of regional and global growth in the past years. The goal is to analyze whether the predictive relationships in the region are mainly driven by this country. As panel D shows, results present similar predictive relationships in both scenarios. However, we do find a slight decrease in the information content of stock return when we exclude China. Conversely, the predictive power of the default spread and global commodity returns improves under this new scenario.

\subsection{GDP per Capita}

As part of our robustness analysis, we split our panel based on GDP per capita. We grouped the countries in our sample into three categories: high, middle and low income. ${ }^{31}$ Table 17 presents results for this new setting. Overall, results for our set of financial aggregates are validated. However, we do find some differences across groups. In particular, stock and commodity returns present the strongest predictive power in our group of middle-income countries. Flows prove to be a helpful predictor across groups, with strongest economic significance in low-income countries. On the other hand, the set of interest rate variables show evidence of predictability in only the middleand low-income countries.

\footnotetext{
${ }^{31}$ High income is composed by countries with a PPP-adjusted GDP per capita higher than 13,000 USD per year. This group includes Taiwan, South Korea, Israel, Czech Republic, Hungary and Poland. GDP per capita for middle income countries ranges from 13,000 USD to 9,000 USD per year. Russia, Argentina, Chile, Malaysia, Mexico, Turkey, Brazil and South Africa fall in this category. GDP per capita for low income countries covers those with less than 9,000 USD per year. In this group we consider Peru, Thailand, China, Egypt, Morocco, Indonesia, Philippines and India.
} 


\subsection{Multivariate Regressions}

We also test the predictive power of the set of financial aggregates to forecast GDP growth in a multivariate setting. In doing so, we group our variables into four categories; namely, return and valuation measures, interest rates, flows and commodities. We use principal component analysis to reduce the number of predictors while still accounting for most of the variance in the observed variables. As shown in table 18, results suggest that our four sets of variables can be useful predictors of one-quarter-ahead GDP growth. In particular, coefficients related to commodities and return and valuation measures are positive and significant when forecasting one quarter ahead output growth. On the other hand, interest rate variables show a negative predictive relationship with subsequent GDP. Also, estimates for flows are positive and statistically significant under the pooled and fixed effects estimation. When we extend the forecasting horizon to one year, only commodities, and return and valuation estimates contain information about future growth. Finally, when forecasting two years ahead, only our measure of flows shows evidence of predictive power. In particular, results suggest a reversal in the predictive relationship of flows and economic activity.

\subsection{Cross-Validation Analysis}

For robustness, we also perform a cross validation exercise to check the stability of our estimates. The goal is to study whether results are driven by a particular country. In a bivariate setting that includes lagged GDP and the variable of interest as the regressors, we randomly exclude three countries from our sample and estimate coefficients and t-statistics. We repeat this exercise twenty times for each variable. Table 19 presents results for this analysis. ${ }^{32}$ For each variable we report the average estimate, its standard deviation and the number of times (out of the twenty random draws) that the coefficient is statistically significant. Results provide evidence in favor of the stability of our estimates across models and horizons. The predictive ability of the variables that proved helpful in our baseline case are validated by this analysis.

\footnotetext{
${ }^{32}$ For convenience, we present results only for financial aggregates. Results for lagged GDP are available upon request.
} 


\section{Conclusion}

This paper contributes to the empirical macro-finance literature by studying the predictive relationship between financial aggregates and economic growth in emerging markets. To address this question, we develop a comprehensive data set on output growth, country-specific and global financial aggregates for a large panel of developing countries, and test for output growth predictability using panel methods that are robust to endogenous and persistent predictors (Hjalmarsson, 2010). Our analysis provides evidence of predictability and shows that a set of financial variables can be used as leading indicators of economic activity in emerging markets. In particular, we find evidence that stock returns, portfolio flows, sovereign default spreads, and commodity prices, among other financial aggregates, can be useful predictors of emerging markets growth. ${ }^{33}$

Our results are also robust to the inclusion of global shocks, which are of particular relevance in the context of emerging markets, as it is well known that these countries can be more vulnerable to external shocks and episodes of contagion. We also recognize the heterogeneity of the countries in the panel and the different economic conditions encompassed in our sample and perform a series of checks aimed at testing the robustness of our results under different escenarios. These checks include testing for predictability using subsamples based on income level and regional location. We also break the panel into subperiods and find that results are robust to the most recent financial crisis.

Overall, by identifying a set of leading indicators for emerging markets, our results can be useful to policy makers and market participants who try to understand and predict the business cycles of these developing economies.

\footnotetext{
${ }^{33}$ We take no stand on whether this finding indicates a causal relation or whether it simply reflects information in forward-looking financial aggregates.
} 


\section{References}

Arellano, C., And E. G. Mendoza (2002): “Credit Frictions and 'Sudden Stops' in Small Open Economies: An Equilibrium Business Cycle Framework for Emerging Markets Crises," NBER Working Papers 8880, National Bureau of Economic Research, Inc.

Bekaert, G., C. R. Harvey, and C. Lundblad (2007): "Liquidity and Expected Returns: Lessons from Emerging Markets," Review of Financial Studies, 20(6), 1783-1831.

Bernanke, B. S., C. C. Bertaut, L. Demarco, and S. B. Kamin (2011): "International Capital Flows and the Return to Safe Assets in the United States, 2003-2007," SSRN eLibrary.

Calvo, G. A. (1998): "Capital Flows and Capital-Market Crises: The Simple Economics of Sudden Stops," Journal of Applied Economics, 0, 35-54.

Chen, Y.-C., K. S. Rogoff, and B. Rossi (2010): "Can Exchange Rates Forecast Commodity Prices?," The Quarterly Journal of Economics, 125(3), 1145-1194.

Dotsey, M. (1998): "The predictive content of the interest rate term spread for future economic growth," Economic Quarterly, (Sum), 31-51.

Estrella, A., and G. A. Hardouvelis (1991): "The Term Structure as a Predictor of Real Economic Activity," Journal of Finance, 46(2), 555-76.

Estrella, A., and F. S. Mishkin (1998): "Predicting U.S. Recessions: Financial Variables As Leading Indicators," The Review of Economics and Statistics, 80(1), 45-61.

Fama, E. F., And K. R. French (1993): "Common risk factors in the returns on stocks and bonds," Journal of Financial Economics, 33(1), 3-56.

Fernndez-Villaverde, J., P. A. Guerron-Quintana, J. Rubio-Ramirez, and M. Uribe (2011): "Risk Matters: The Real Effects of Volatility Shocks," American Economic Review, (01(6): 253061).

Ferretti, G. M. M., And A. Razin (2000): "Current Account Reversals and Currency Crises, Empirical Regularities," in Currency Crises, NBER Chapters, pp. 285-326. National Bureau of Economic Research, Inc. 
Frankel, J., and G. Saravelos (2012): "Can leading indicators assess country vulnerability? Evidence from the 200809 global financial crisis," Journal of International Economics, 87(2), 216 $-231$.

Gilchrist, S., V. Yankov, and E. Zakrajsek (2009): "Credit market shocks and economic fluctuations: Evidence from corporate bond and stock markets," Journal of Monetary Economics, 56(4), 471-493.

Hamilton, J. D. (2003): "What is an oil shock?," Journal of Econometrics, 113(2), 363 - 398.

(2010): "Nonlinearities and the Macroeconomic Effects of Oil Prices," SSRN eLibrary.

Hamilton, J. D., And D. H. Kim (2002): "A Reexamination of the Predictability of Economic Activity Using the Yield Spread," Journal of Money, Credit and Banking, 34(2), 340-60.

HARVEY, C. R. (1988): "The real term structure and consumption growth," Journal of Financial Economics, 22(2), 305-333.

(1989): "Forecasts of Economic Growth from the Bond and Stock Markets," Financial Analysts Journal, 45(5), pp. 38-45.

_ (1994): "Conditional Asset Allocation in Emerging Markets," NBER Working Papers 4623, National Bureau of Economic Research, Inc.

Harvey, C. R. (1995): "Predictable Risk and Returns in Emerging Markets," Review of Financial Studies, 8(3), 773-816.

Haubrich, J. G., And A. M. Dombrosky (1996): "Predicting real growth using the yield curve," Economic Review, (Q I), 26-35.

HJalmarsson, E. (2007): "The Stambaugh Bias in Panel Predictive Regressions," SSRN eLibrary. (2010): "Predicting Global Stock Returns," Journal of Financial and Quantitative Analysis, 45(01), 49-80.

Hodrick, R. J. (1992): "Dividend Yields and Expected Stock Returns: Alternative Procedures for Inference and Measurement," Review of Financial Studies, 5(3), 357-86. 
Kucko, K., And M. Chin (2009): "The Predictive Power of the Yield Curve Across Countries and Time," .

Liew, J., And M. VAssalou (2000): "Can book-to-market, size and momentum be risk factors that predict economic growth?," Journal of Financial Economics, 57(2), 221 - 245.

MAuro, P. (2003): "Stock returns and output growth in emerging and advanced economies," Journal of Development Economics, 71(1), 129-153.

Neumeyer, P. A., And F. Perri (2005): "Business cycles in emerging economies: the role of interest rates," Journal of Monetary Economics, 52(2), 345-380.

Perez-Quiros, G., and A. Timmermann (2001): "Business cycle asymmetries in stock returns: Evidence from higher order moments and conditional densities," Journal of Econometrics, 103(12), $259-306$.

Reinhart, C., and G. Calvo (2000): "When Capital Inflows Come to a Sudden Stop: Consequences and Policy Options," MPRA Paper 6982, University Library of Munich, Germany.

Stambaugh, R. F. (1999): "Predictive regressions," Journal of Financial Economics, 54(3), 375421.

Stock, J. H., And M. W. Watson (1989): "New Indexes of Coincident and Leading Economic Indicators," in NBER Macroeconomics Annual 1989, Volume 4, NBER Chapters, pp. 351-409. National Bureau of Economic Research, Inc.

(2003): "Forecasting Output and Inflation: The Role of Asset Prices," Journal of Economic Literature, 41(3), 788-829.

WeBer, C. E. (1998): "Consumption Spending and the Paper-Bill Spread: Theory and Evidence," Economic Inquiry, 36(4), 575-89.

Wei, M., And J. H. Wright (2010): "Reverse Regressions and Long-Horizon Forecasting," . 
Table 1: GDP Growth Summary Statistics

\begin{tabular}{|c|c|c|c|c|c|c|c|}
\hline Country & Dates & Obs. & Mean & StdDev & Skewness & Kurtosis & $\operatorname{AR}(1)$ \\
\hline Argentina & Q1 1993-Q1 2010 & 68 & 0.896 & 2.940 & -0.055 & 11.379 & 0.3546 \\
\hline Brazil & Q1 1995-Q1 2010 & 60 & 0.859 & 2.435 & 0.758 & 16.564 & -0.244 \\
\hline China & Q4 1999-Q4 2009 & 40 & 3.047 & 2.326 & 4.222 & 24.328 & 0.0495 \\
\hline Chile & Q1 1996-Q4 2009 & 55 & 0.887 & 1.226 & -1.099 & 5.078 & 0.307 \\
\hline Czech Republic & Q1 1994-Q1 2010 & 64 & 0.839 & 1.585 & 0.999 & 9.080 & 0.076 \\
\hline Egypt & Q1 2002-Q4 2009 & 31 & 1.312 & 1.246 & 1.143 & 4.890 & -0.2657 \\
\hline Hungary & Q1 1995-Q1 2010 & 60 & 0.659 & 1.050 & -1.409 & 6.071 & 0.5148 \\
\hline Indonesia & Q1 1997-Q1 2010 & 52 & 0.862 & 2.256 & -4.002 & 19.399 & 0.4188 \\
\hline India & Q1 2004-Q4 2009 & 50 & 1.408 & 1.891 & 0.212 & 3.985 & 0.4869 \\
\hline Israel & Q4 1992-Q1 2010 & 69 & 1.005 & 1.598 & 0.322 & 3.546 & -0.1459 \\
\hline Korea & Q4 1992-Q4 2009 & 68 & 1.220 & 1.876 & -2.862 & 16.598 & 0.1797 \\
\hline Malaysia & Q4 1992-Q4 2009 & 68 & 1.340 & 1.700 & -1.477 & 5.785 & 0.5994 \\
\hline Mexico & Q4 1992-Q1 2010 & 69 & 0.608 & 1.698 & -2.338 & 9.797 & 0.3369 \\
\hline Morocco & Q4 1992-Q4 2009 & 68 & 1.099 & 4.160 & 0.499 & 5.463 & -0.4559 \\
\hline Peru & Q4 1992-Q4 2009 & 68 & 1.283 & 1.526 & -0.626 & 2.832 & 0.3127 \\
\hline Philippines & Q4 1992-Q1 2010 & 69 & 1.284 & 1.271 & 3.023 & 20.185 & 0.1233 \\
\hline Poland & Q1 1995-Q4 2009 & 59 & 1.141 & 1.525 & 0.039 & 6.921 & -0.2384 \\
\hline Russia & Q1 1995-Q3 2009 & 58 & 0.887 & 2.551 & -2.316 & 11.466 & 0.097 \\
\hline South Africa & Q4 1992-Q4 2009 & 68 & 1.131 & 1.689 & 0.319 & 6.888 & -0.0804 \\
\hline Taiwan & Q4 1992-Q1 2010 & 69 & 1.165 & 1.604 & -1.621 & 8.458 & 0.3495 \\
\hline Thailand & Q1 1993-Q1 2010 & 68 & 1.004 & 2.067 & -0.855 & 5.238 & 0.393 \\
\hline Turkey & Q4 1992-Q4 2009 & 68 & 0.976 & 2.870 & -1.109 & 4.377 & 0.075 \\
\hline
\end{tabular}

Table 1 shows descriptive statistics for real seasonally adjusted GDP growth of emerging market countries. AR(1) represents the autocorrelation coefficient. The sample spans from December 1992 to March 2010. GDP series are at the quarterly frequency. 


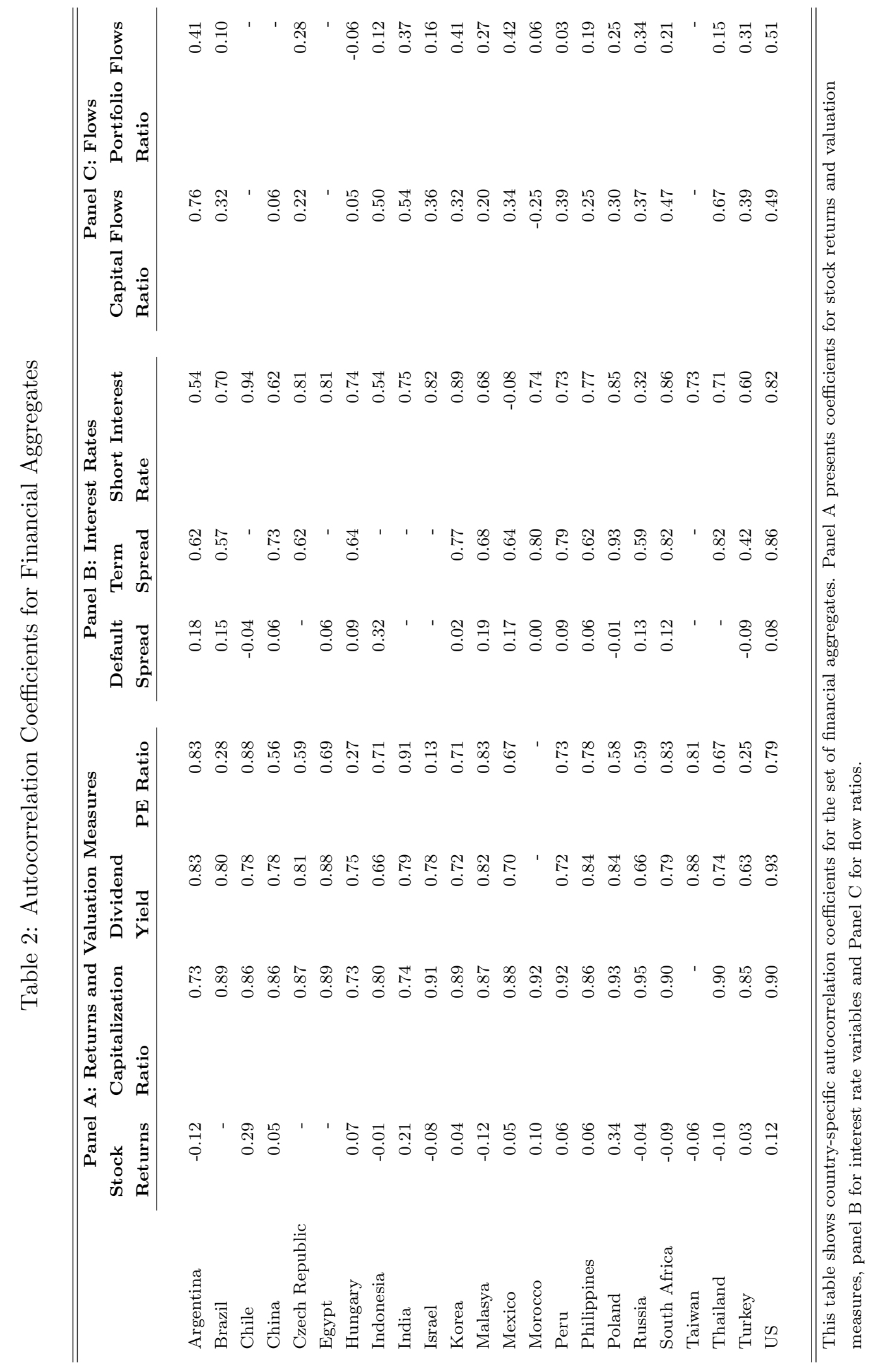




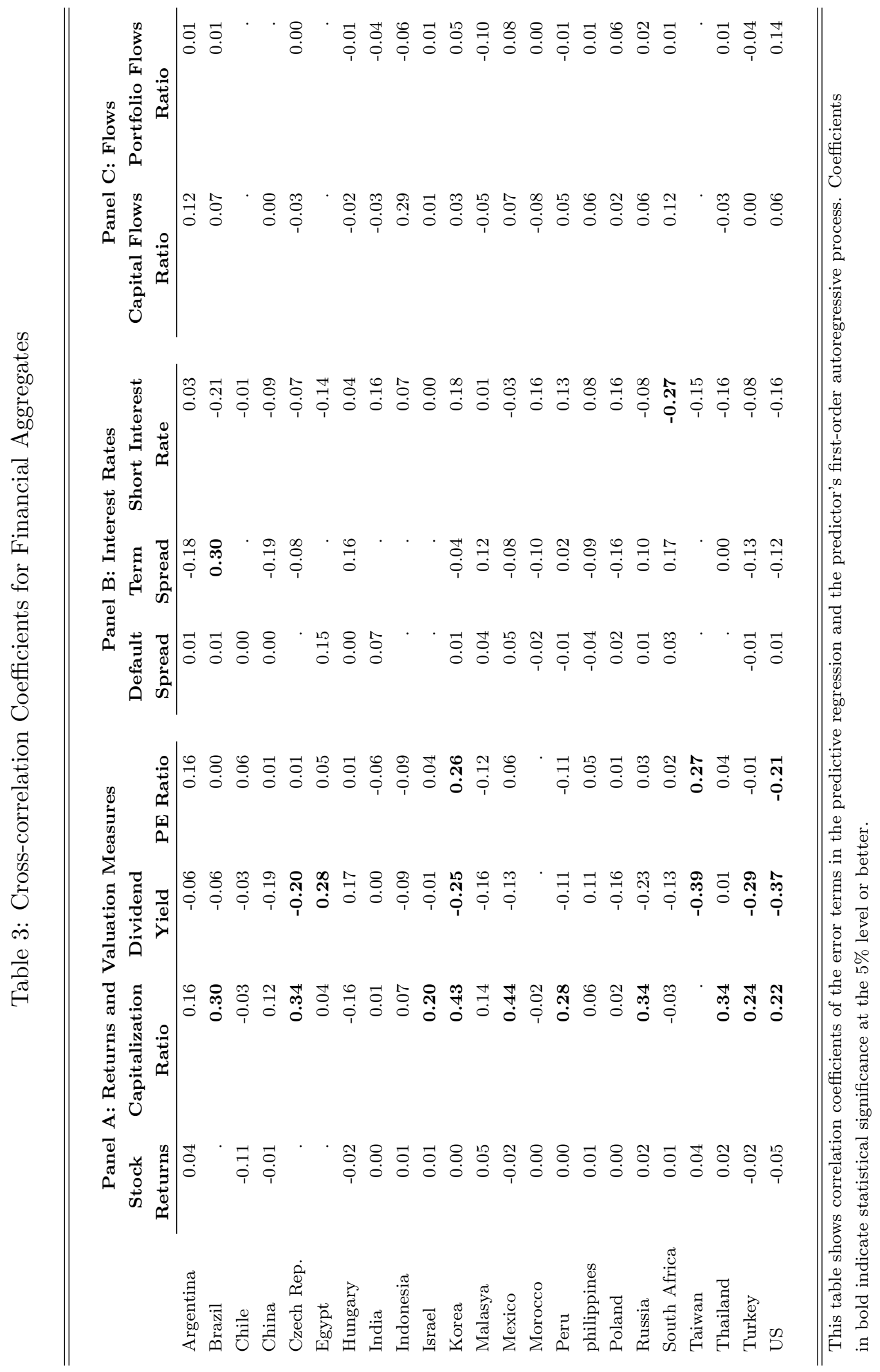




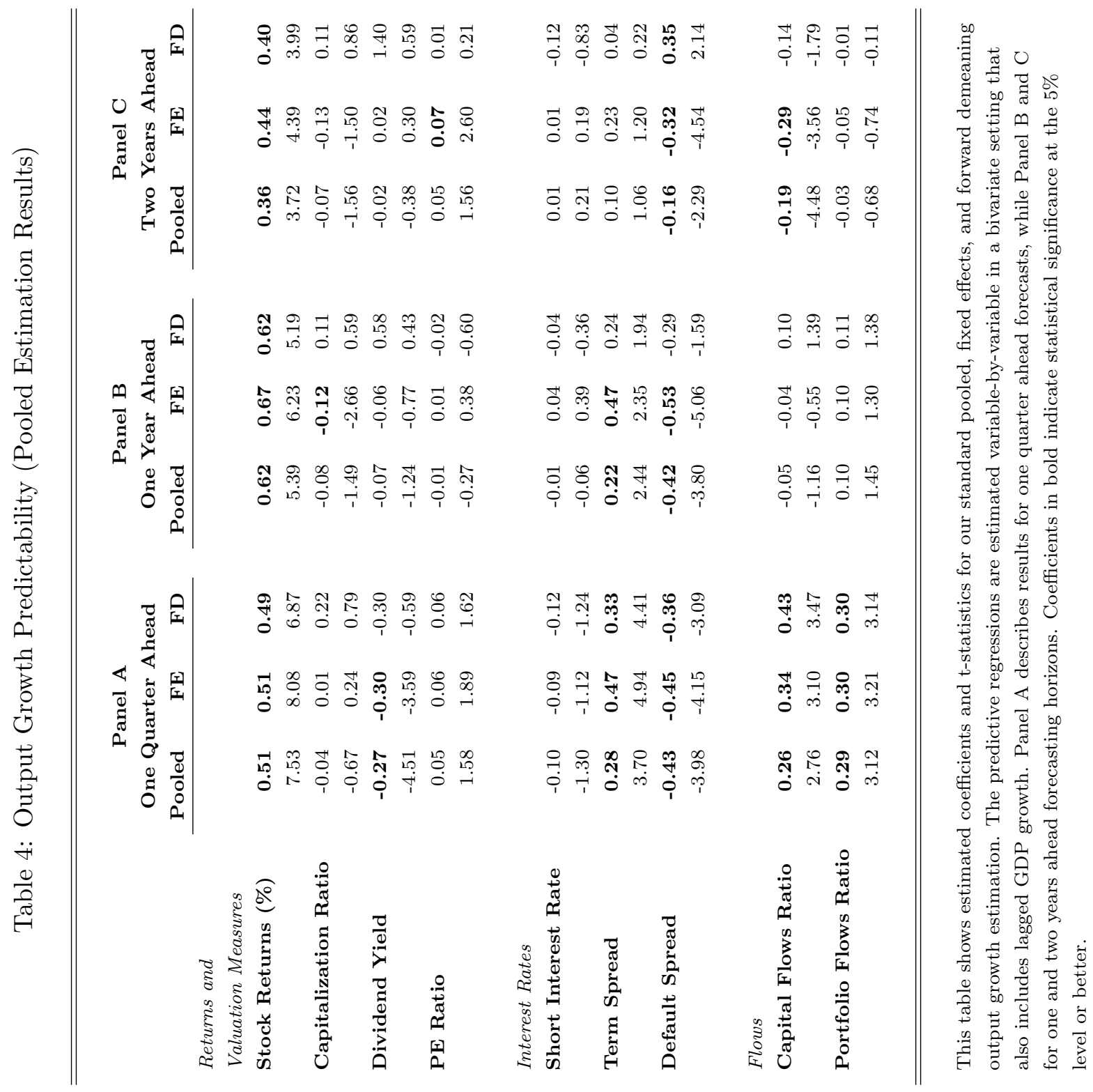


Table 5: Country Level Estimation: Returns and Valuation Measures

\begin{tabular}{|c|c|c|c|c|c|c|c|c|}
\hline & \multicolumn{2}{|c|}{ Stock Returns } & \multicolumn{2}{|c|}{ Cap. Ratio } & \multicolumn{2}{|c|}{ PE Ratio } & \multicolumn{2}{|c|}{ Dividend Yield } \\
\hline & Beta & T-stat & Beta & T-stat & Beta & T-stat & Beta & T-stat \\
\hline Argentina & 0.05 & 2.08 & 18.87 & 2.30 & 0.10 & 1.87 & -0.47 & -2.02 \\
\hline Brazil & - & - & 0.45 & 1.57 & -0.03 & -0.59 & -0.44 & -2.16 \\
\hline China & 0.03 & 1.72 & 0.03 & 0.17 & -0.05 & -2.45 & 0.84 & 1.64 \\
\hline Chile & 0.01 & 0.70 & 0.45 & 1.28 & 0.08 & 0.86 & -0.43 & -1.44 \\
\hline Czech Rep. & - & - & -0.90 & -1.10 & 0.00 & 0.73 & -0.04 & -0.55 \\
\hline Egypt & - & - & 0.45 & 3.86 & 0.08 & 2.26 & -0.08 & -1.72 \\
\hline Hungary & 0.01 & 0.74 & 0.00 & -1.87 & 0.00 & -3.01 & -0.56 & -4.00 \\
\hline Indonesia & 0.01 & 1.20 & 1.07 & 1.71 & 0.03 & 0.66 & -0.06 & -0.24 \\
\hline India & 0.00 & 0.12 & -1.09 & -1.57 & -0.03 & -0.44 & 0.75 & 1.22 \\
\hline Israel & 0.04 & 3.82 & 0.09 & 0.75 & 0.00 & 0.23 & -0.12 & -1.17 \\
\hline South Korea & 0.04 & 2.37 & 0.00 & 0.89 & 0.11 & 2.89 & -1.86 & -2.96 \\
\hline Malaysia & 0.03 & 2.10 & 0.24 & 3.43 & 0.09 & 2.50 & -0.48 & -2.68 \\
\hline Mexico & 0.07 & 2.96 & 0.00 & 0.44 & 0.01 & 0.04 & -1.91 & -2.68 \\
\hline Morocco & -0.01 & -0.46 & -7.47 & -0.49 & - & - & - & - \\
\hline Peru & 0.03 & 2.80 & 0.58 & 0.68 & 0.04 & 2.10 & -0.22 & -1.74 \\
\hline Philippines & 0.00 & 0.20 & -0.01 & -0.41 & 0.00 & 0.19 & 0.44 & 1.91 \\
\hline Poland & 0.01 & 0.98 & -0.33 & -0.15 & -0.01 & -0.18 & -0.09 & -0.71 \\
\hline Russia & 0.02 & 1.38 & 0.01 & 1.58 & 0.06 & 3.43 & -1.15 & -1.77 \\
\hline South Africa & 0.02 & 1.04 & 0.00 & -0.47 & -0.03 & -0.51 & 0.38 & 1.05 \\
\hline Taiwan & 0.03 & 2.48 & - & - & 0.06 & 2.22 & -0.17 & -1.03 \\
\hline Thailand & 0.04 & 4.68 & 3.79 & 1.78 & 0.04 & 1.49 & -0.50 & -2.40 \\
\hline Turkey & 0.04 & 2.49 & 32.38 & 1.10 & 0.00 & 1.40 & -0.25 & -0.58 \\
\hline
\end{tabular}

This table presents results for our time series predictive regressions over the entire sample period. We run bivariate regressions for the set of return and valuation measures and use Newey-West standard errors. Coefficients in bold indicate statistical significance at the $5 \%$ level or better. 
Table 6: Country Level Estimation: Interest Rates

\begin{tabular}{|c|c|c|c|c|c|c|}
\hline & \multicolumn{2}{|c|}{ Default Spread } & \multicolumn{2}{|c|}{ Term Spread } & \multicolumn{2}{|c|}{$\begin{array}{c}\text { Short Interest } \\
\text { Rate }\end{array}$} \\
\hline & Beta & T-stat & Beta & T-stat & Beta & T-stat \\
\hline Argentina & -0.03 & -4.91 & 0.06 & 3.32 & -0.08 & -2.68 \\
\hline Brazil & -0.01 & -1.30 & 0.00 & -0.13 & -0.06 & -2.67 \\
\hline China & 0.00 & 0.27 & - & - & -0.18 & -1.14 \\
\hline Chile & -0.01 & -0.58 & 0.34 & 2.04 & -0.03 & -1.31 \\
\hline Czech Rep. & - & - & 0.07 & 0.70 & -0.22 & -1.59 \\
\hline Egypt & 0.00 & 0.84 & - & - & -0.06 & -1.35 \\
\hline Hungary & -0.01 & -0.95 & -0.23 & -2.11 & -0.15 & -1.40 \\
\hline Indonesia & -0.01 & -2.69 & - & - & 0.02 & 0.84 \\
\hline India & - & - & - & - & 0.04 & 0.41 \\
\hline Israel & - & - & - & - & 0.02 & 0.34 \\
\hline South Korea & -0.02 & -6.94 & 0.50 & 1.30 & 0.08 & 0.80 \\
\hline Malaysia & -0.02 & -3.79 & 0.25 & 1.09 & 0.09 & 0.38 \\
\hline Mexico & -0.03 & -2.01 & 0.17 & 1.13 & -0.03 & -1.02 \\
\hline Morocco & -0.01 & -0.68 & 0.26 & 1.02 & 0.03 & 0.24 \\
\hline Peru & -0.02 & -2.52 & 0.05 & 2.81 & -0.05 & -2.28 \\
\hline Philippines & 0.00 & -0.61 & 0.01 & 0.15 & -0.07 & -1.75 \\
\hline Poland & 0.00 & -2.67 & 0.09 & 1.68 & -0.07 & -1.32 \\
\hline Russia & -0.01 & -0.80 & 0.04 & 0.57 & 0.00 & -0.35 \\
\hline South Africa & 0.00 & -0.30 & 0.29 & 2.73 & -0.02 & -0.16 \\
\hline Taiwan & - & - & - & - & 0.09 & 0.60 \\
\hline Thailand & - & - & 0.54 & 3.26 & -0.07 & -0.64 \\
\hline Turkey & -0.01 & -0.36 & 0.37 & 0.91 & 0.00 & 0.30 \\
\hline
\end{tabular}

This table presents results for our time series predictive regressions over the entire sample period. We run bivariate regressions for the set of return and valuation measures and use Newey-West standard errors. Coefficients in bold indicate statistical significance at the $5 \%$ level or better. 


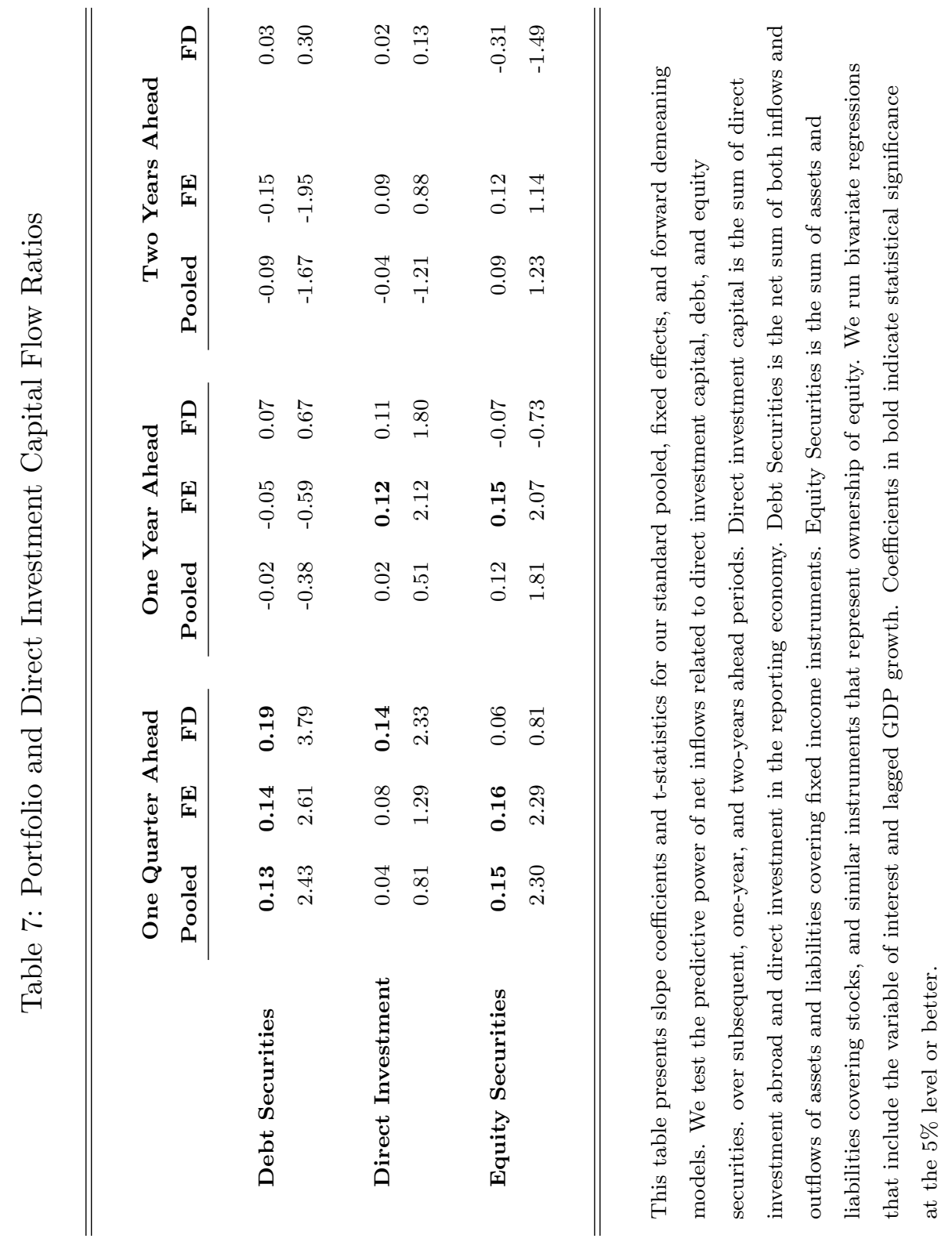


Table 8: Country Level Estimation: Flows Ratios

\begin{tabular}{|c|c|c|c|c|}
\hline & \multicolumn{2}{|c|}{ Capital Flows } & \multicolumn{2}{|c|}{ Portfolio Flows } \\
\hline & Beta & T-stat & Beta & T-stat \\
\hline Argentina & 8.74 & 0.44 & 27.70 & 1.43 \\
\hline Brazil & 17.60 & 2.20 & 25.31 & 2.73 \\
\hline Chile & -2.09 & -0.62 & - & - \\
\hline Czech Rep. & 2.99 & 0.82 & 0.47 & 0.10 \\
\hline Hungary & 2.66 & 1.85 & 3.75 & 1.24 \\
\hline Indonesia & 31.93 & 3.47 & 3.75 & 2.16 \\
\hline India & 17.38 & 0.80 & 42.57 & 1.12 \\
\hline Israel & -2.48 & -1.08 & 4.51 & 1.05 \\
\hline South Korea & 21.41 & 2.43 & 6.82 & 1.11 \\
\hline Malaysia & 5.07 & 1.67 & 7.14 & 1.78 \\
\hline Mexico & 58.01 & 1.66 & 94.48 & 2.64 \\
\hline Morocco & 5.33 & 1.13 & 38.12 & 1.01 \\
\hline Peru & 8.66 & 2.35 & 18.49 & 2.55 \\
\hline Philippines & -0.97 & -0.93 & 7.69 & 2.84 \\
\hline Poland & -0.97 & -0.95 & 7.69 & 4.67 \\
\hline Russia & 4.80 & 0.57 & 2.90 & 0.22 \\
\hline South Africa & 29.15 & 1.42 & 7.76 & 0.48 \\
\hline Thailand & 8.83 & 2.09 & -0.89 & -0.08 \\
\hline Turkey & -0.25 & -0.04 & 11.20 & 0.51 \\
\hline
\end{tabular}

This table presents results for our time series predictive regressions over the entire sample period. We run bivariate regressions for the measures of flows and use Newey-West standard errors. Coefficients in bold indicate statistical significance at the $5 \%$ level or better. 


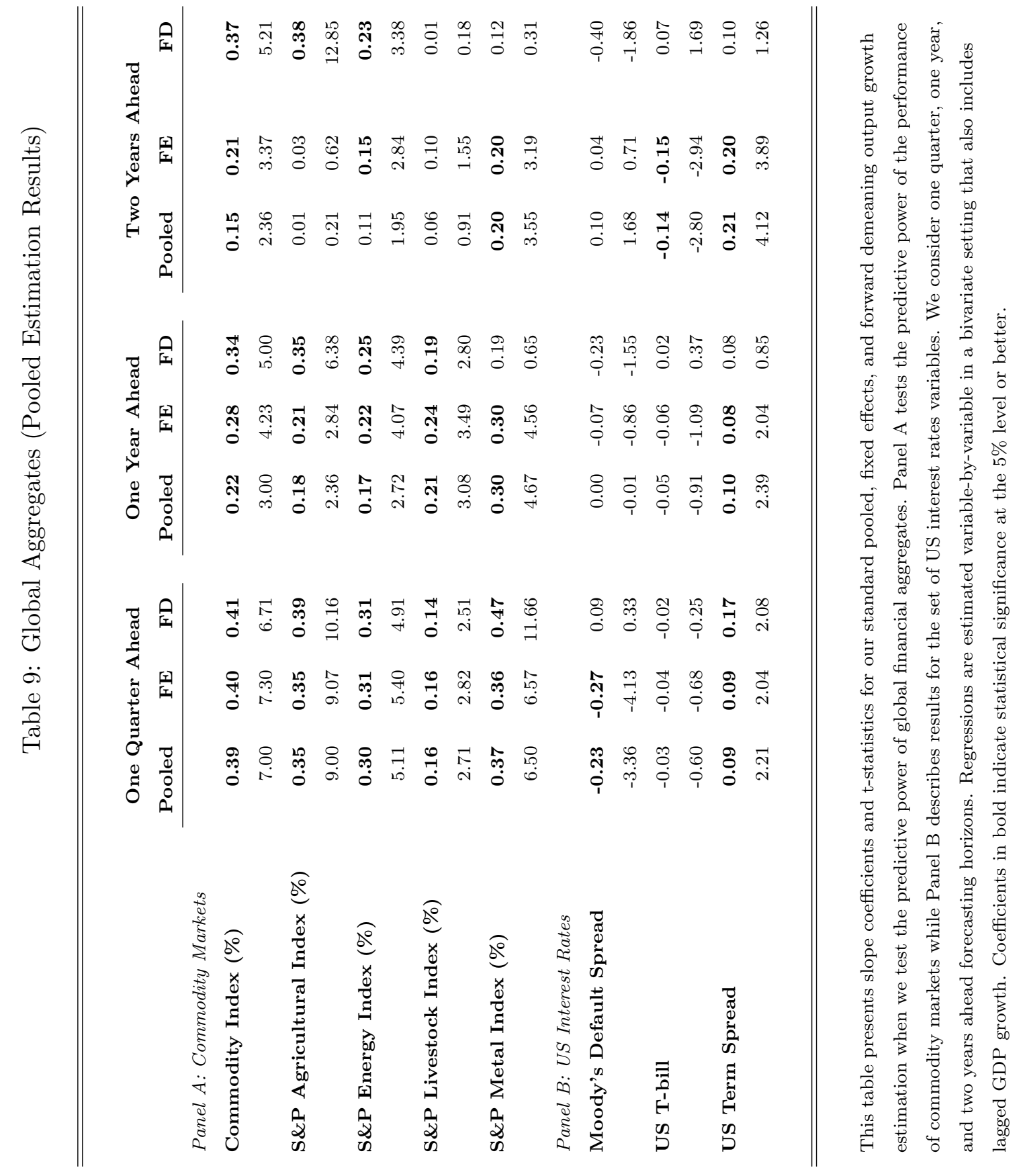


Table 10: Country Level Estimation: Commodity Markets

\begin{tabular}{|c|c|c|c|c|c|c|c|c|c|c|}
\hline & \multicolumn{2}{|c|}{ Commodities } & \multicolumn{2}{|c|}{ Energy } & \multicolumn{2}{|c|}{ Agriculture } & \multicolumn{2}{|c|}{ Livestock } & \multicolumn{2}{|c|}{ Precious Metals } \\
\hline & Beta & T-stat & Beta & T-stat & Beta & T-stat & Beta & T-stat & Beta & T-stat \\
\hline Argentina & 0.03 & 1.23 & 0.01 & 0.36 & 0.05 & 1.36 & 0.03 & 0.97 & 0.15 & 2.29 \\
\hline Brazil & 0.05 & 2.71 & 0.02 & 1.26 & 0.08 & 3.54 & 0.04 & 1.38 & 0.08 & 3.02 \\
\hline China & 0.00 & 0.05 & -0.01 & -0.48 & 0.04 & 1.53 & 0.05 & 1.43 & 0.12 & 1.97 \\
\hline Chile & 0.03 & 3.28 & 0.02 & 2.22 & 0.04 & 1.77 & 0.01 & 0.63 & 0.04 & 1.09 \\
\hline Czech Rep. & 0.06 & 3.92 & 0.04 & 2.98 & 0.05 & 2.34 & 0.02 & 0.91 & 0.01 & 0.21 \\
\hline Egypt & 0.00 & 0.10 & 0.00 & -0.13 & 0.03 & 2.45 & 0.02 & 0.80 & 0.04 & 1.49 \\
\hline Hungary & 0.04 & 2.27 & 0.02 & 2.01 & 0.02 & 1.01 & 0.02 & 1.50 & 0.00 & 0.11 \\
\hline Indonesia & 0.04 & 1.38 & 0.03 & 1.40 & 0.01 & 0.65 & 0.00 & 0.13 & 0.06 & 1.29 \\
\hline India & 0.02 & 1.42 & 0.01 & 0.91 & 0.02 & 0.79 & 0.08 & 2.27 & 0.00 & 0.03 \\
\hline Israel & 0.03 & 1.44 & 0.02 & 1.36 & 0.03 & 1.56 & -0.01 & -0.27 & 0.03 & 1.05 \\
\hline South Korea & 0.04 & 2.17 & 0.03 & 1.84 & 0.04 & 2.12 & 0.05 & 2.01 & 0.09 & 1.67 \\
\hline Malaysia & 0.06 & 3.61 & 0.04 & 3.21 & 0.05 & 2.33 & 0.02 & 0.68 & 0.07 & 2.40 \\
\hline Mexico & 0.06 & 2.12 & 0.04 & 1.92 & 0.03 & 1.00 & 0.02 & 0.69 & 0.02 & 1.02 \\
\hline Morocco & -0.05 & -2.03 & -0.04 & -1.88 & 0.00 & -0.10 & 0.06 & 1.03 & 0.14 & 1.66 \\
\hline Peru & 0.02 & 1.14 & 0.01 & 0.35 & 0.05 & 2.68 & -0.03 & -1.53 & 0.08 & 3.43 \\
\hline Philippines & 0.02 & 3.21 & 0.01 & 2.45 & 0.01 & 0.94 & 0.06 & 1.84 & 0.03 & 1.46 \\
\hline Poland & 0.02 & 2.60 & 0.01 & 2.16 & 0.04 & 3.90 & -0.03 & -1.11 & 0.03 & 1.28 \\
\hline Russia & 0.10 & 2.72 & 0.07 & 2.37 & 0.04 & 1.40 & 0.08 & 2.22 & 0.07 & 1.30 \\
\hline South Africa & 0.02 & 1.33 & 0.00 & 0.29 & 0.05 & 2.75 & 0.05 & 1.46 & 0.03 & 1.52 \\
\hline Taiwan & 0.04 & 1.88 & 0.02 & 1.31 & 0.05 & 1.59 & 0.01 & 0.78 & 0.07 & 1.95 \\
\hline Thailand & 0.04 & 1.89 & 0.02 & 1.12 & 0.06 & 2.04 & -0.02 & -0.70 & 0.10 & 2.32 \\
\hline Turkey & 0.07 & 2.83 & 0.05 & 2.28 & 0.07 & 2.42 & 0.00 & 0.06 & 0.05 & 0.68 \\
\hline
\end{tabular}

This table presents results for our time series predictive regressions over the entire sample period. We run bivariate regressions for the set of returns on commodity markets and use Newey-West standard errors. Coefficients in bold indicate statistical significance at the $5 \%$ level or better. 
Table 11: Country Level Estimation: US Interest Rates

\begin{tabular}{|c|c|c|c|c|c|c|}
\hline & \multicolumn{2}{|c|}{ Term Spread } & \multicolumn{2}{|c|}{ T-bill } & \multicolumn{2}{|c|}{ Default Spread } \\
\hline & Beta & T-stat & Beta & T-stat & Beta & T-stat \\
\hline Argentina & 0.19 & 0.57 & -0.36 & -1.60 & -0.32 & -0.67 \\
\hline Brazil & 0.09 & 0.54 & 0.09 & 0.62 & -0.38 & -0.95 \\
\hline China & 0.30 & 0.96 & -0.41 & -2.22 & -0.24 & -0.66 \\
\hline Chile & 0.07 & 0.38 & 0.05 & 0.37 & -0.72 & -3.20 \\
\hline Czech Rep. & 0.01 & 0.07 & 0.08 & 0.64 & -1.15 & -3.29 \\
\hline Egypt & -0.18 & -1.89 & 0.07 & 0.60 & -0.36 & -2.24 \\
\hline Hungary & -0.08 & -0.51 & 0.11 & 0.93 & -1.20 & -4.25 \\
\hline Indonesia & 0.28 & 1.01 & -0.32 & -1.19 & 0.56 & 0.90 \\
\hline India & -0.12 & -0.40 & -0.24 & -1.49 & -1.47 & -3.15 \\
\hline Israel & -0.11 & -0.95 & 0.13 & 1.75 & -0.65 & -3.18 \\
\hline South Korea & 0.13 & 0.68 & 0.17 & 0.73 & -0.28 & -0.61 \\
\hline Malaysia & 0.34 & 1.63 & 0.04 & 0.17 & -0.66 & -1.20 \\
\hline Mexico & -0.14 & -1.24 & 0.15 & 1.07 & -1.25 & -2.44 \\
\hline Morocco & -0.11 & -0.54 & -0.10 & -0.56 & 0.51 & 1.53 \\
\hline Peru & 0.29 & 1.30 & -0.13 & -1.01 & -0.57 & -1.80 \\
\hline Philippines & 0.08 & 0.56 & -0.19 & -1.94 & 0.26 & 0.71 \\
\hline Poland & -0.18 & -1.39 & 0.12 & 1.77 & -0.48 & -2.66 \\
\hline Russia & 0.04 & 0.15 & -0.12 & -0.59 & -1.61 & -1.55 \\
\hline South Africa & -0.05 & -0.28 & -0.11 & -0.81 & -0.76 & -2.87 \\
\hline Taiwan & 0.19 & 0.97 & 0.21 & 0.94 & -0.45 & -0.85 \\
\hline Thailand & 0.40 & 1.77 & -0.08 & -0.28 & -0.25 & -0.38 \\
\hline Turkey & 0.25 & 0.76 & 0.17 & 0.62 & -0.76 & -1.12 \\
\hline
\end{tabular}

This table presents results for our time series predictive regressions over the entire sample period. We run bivariate regressions for the set of US interest rates and use Newey-West standard errors. Coefficients in bold indicate statistical significance at the $5 \%$ level or better. 


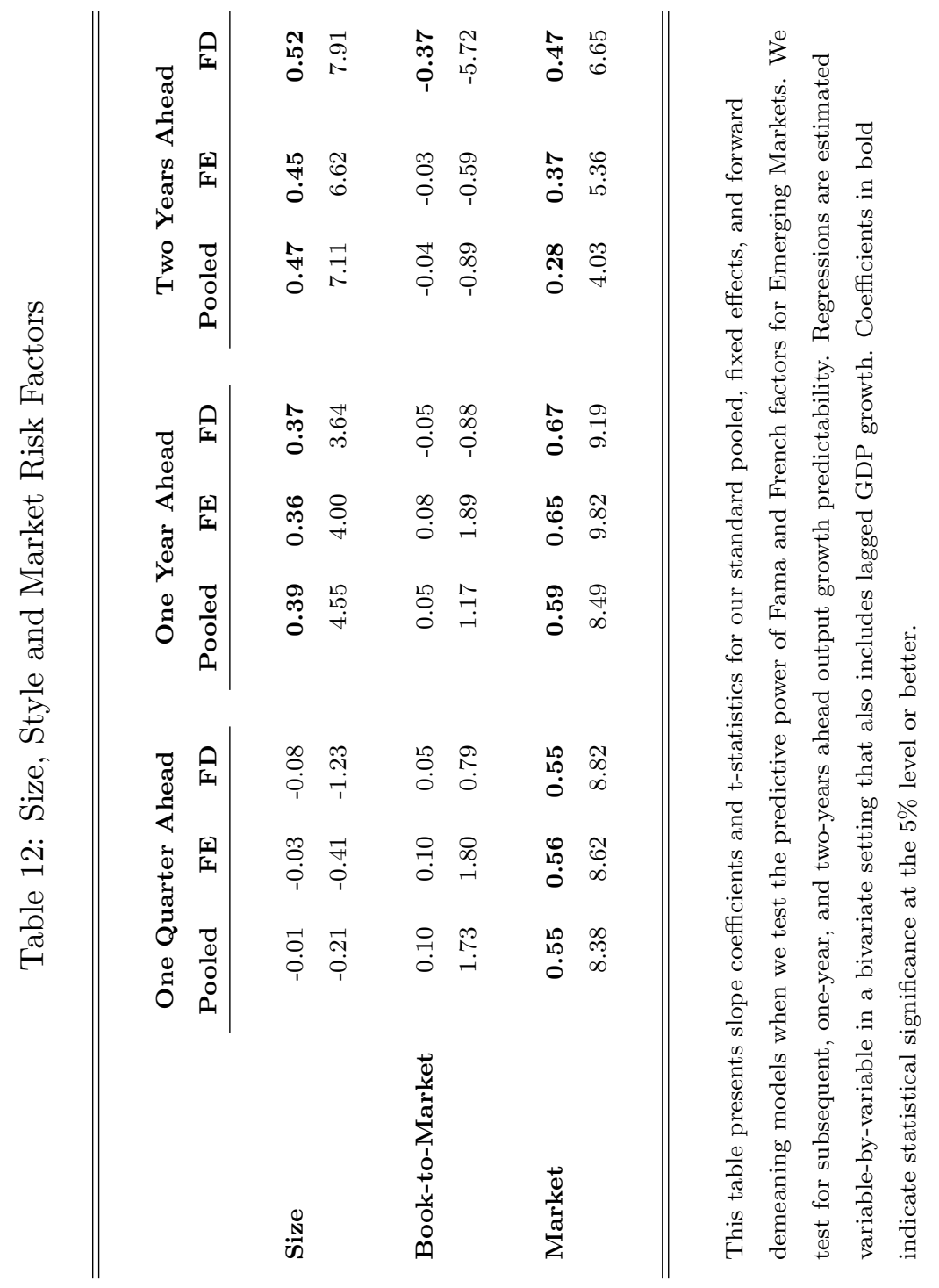


Table 13: Output Growth Predictability in the US

\begin{tabular}{|c|c|c|c|c|}
\hline & Beta & T-stat & Beta GDP & T-stat \\
\hline \multicolumn{5}{|l|}{ Panel A: Return and } \\
\hline \multicolumn{5}{|l|}{ Valuation Measures } \\
\hline Stock Returns (\%) & 0.14 & 1.80 & 0.25 & 2.09 \\
\hline Capitalization Ratio & 0.00 & -0.01 & 0.31 & 2.35 \\
\hline Dividend Yield & -0.04 & -0.63 & 0.30 & 2.39 \\
\hline PE Ratio & 0.03 & 0.38 & 0.33 & 2.04 \\
\hline \multicolumn{5}{|l|}{ Panel B: Interest Rates } \\
\hline Short Interest Rate & 0.18 & 1.90 & 0.26 & 2.39 \\
\hline Term Spread & 0.00 & -0.08 & 0.31 & 2.47 \\
\hline Default Spread & -0.27 & -3.17 & 0.12 & 1.14 \\
\hline \multicolumn{5}{|l|}{ Panel C: Flows } \\
\hline Capital Flows Ratio & -0.16 & -2.04 & 0.30 & 2.23 \\
\hline Portfolio Flows Ratio & -0.13 & -2.12 & 0.29 & 2.35 \\
\hline \multicolumn{5}{|l|}{ Panel D: Commodity Markets } \\
\hline Commodity Index (\%) & -0.04 & -0.46 & 0.33 & 2.59 \\
\hline S\&P Agricultural Index (\%) & -0.02 & -0.27 & 0.32 & 2.51 \\
\hline S\&P Energy Index (\%) & -0.05 & -0.65 & 0.33 & 2.55 \\
\hline S\&P Livestock Index (\%) & 0.05 & 0.98 & 0.31 & 2.48 \\
\hline S\&P Metal Index (\%) & -0.02 & -0.34 & 0.31 & 2.48 \\
\hline \multicolumn{5}{|l|}{ Panel E: Risk Factors } \\
\hline Book-to-market & 0.06 & 0.73 & 0.31 & 2.24 \\
\hline Size & -0.24 & -3.00 & 0.22 & 1.77 \\
\hline
\end{tabular}

This table presents estimation results for the US over the period covering

December 1992 to March 2010. FOr each variable we run bivariate regressions that include lagged GDP growth. We report estimates and t-statistics of the variable of interest and lagged GDP growth. Panel A shows results for returns and valuation measures, Panel B for our set of interest rates variables, Panel C for flows, Panel D for performance of global and sector commodity markets and Panel E for Fama and French risk factors. 
Table 14: Common Factors

\begin{tabular}{|c|c|c|c|}
\hline & \multicolumn{3}{|c|}{ Panel A: Returns and Valuation Measures } \\
\hline & Beta RP & Beta RFE & Beta RFD \\
\hline \multirow[t]{2}{*}{ Stock Returns } & 0.33 & 0.26 & 0.24 \\
\hline & 3.03 & 2.51 & 2.63 \\
\hline \multirow[t]{2}{*}{ Capitalization Ratio } & 0.22 & 0.18 & 0.42 \\
\hline & 1.56 & 1.21 & 0.10 \\
\hline \multirow[t]{2}{*}{ Dividend Yield } & 0.01 & -0.30 & -0.30 \\
\hline & 0.07 & -2.70 & -1.05 \\
\hline \multirow[t]{4}{*}{ PE Ratio } & 0.25 & 0.09 & 0.10 \\
\hline & 2.03 & 1.00 & 0.93 \\
\hline & \multicolumn{3}{|c|}{ Panel B: Interest Rates } \\
\hline & Beta RP & Beta RFE & Beta RFD \\
\hline \multirow[t]{2}{*}{ Short Interest Rate } & -0.11 & -0.16 & -0.22 \\
\hline & -1.41 & -2.05 & -2.17 \\
\hline \multirow[t]{2}{*}{ Term Spread } & 0.39 & 0.63 & 0.55 \\
\hline & 2.04 & 4.05 & 2.32 \\
\hline \multirow[t]{4}{*}{ Default Spread } & -0.15 & -0.24 & -0.24 \\
\hline & -0.66 & -1.13 & -1.04 \\
\hline & \multicolumn{3}{|c|}{ Panel C: Flows } \\
\hline & Beta RP & Beta RFE & Beta RFD \\
\hline \multirow[t]{2}{*}{ Capital Flows Ratio } & 0.30 & 0.31 & 0.39 \\
\hline & 3.31 & 2.89 & 2.78 \\
\hline \multirow[t]{2}{*}{ Portfolio Flows Ratio } & 0.29 & 0.26 & 0.29 \\
\hline & 2.52 & 2.21 & 2.32 \\
\hline
\end{tabular}

This table shows estimated coefficients and t-statistics for our standard pooled, fixed effects, and forward demeaning output growth estimation when we account for common factors in the data generating process. Panel A describes results for returns and valuation measures, Panel B covers interest rates variables, and Panel C portfolio and capital flows. The coefficients in bold indicate statistical significance at the $5 \%$ level or better. 


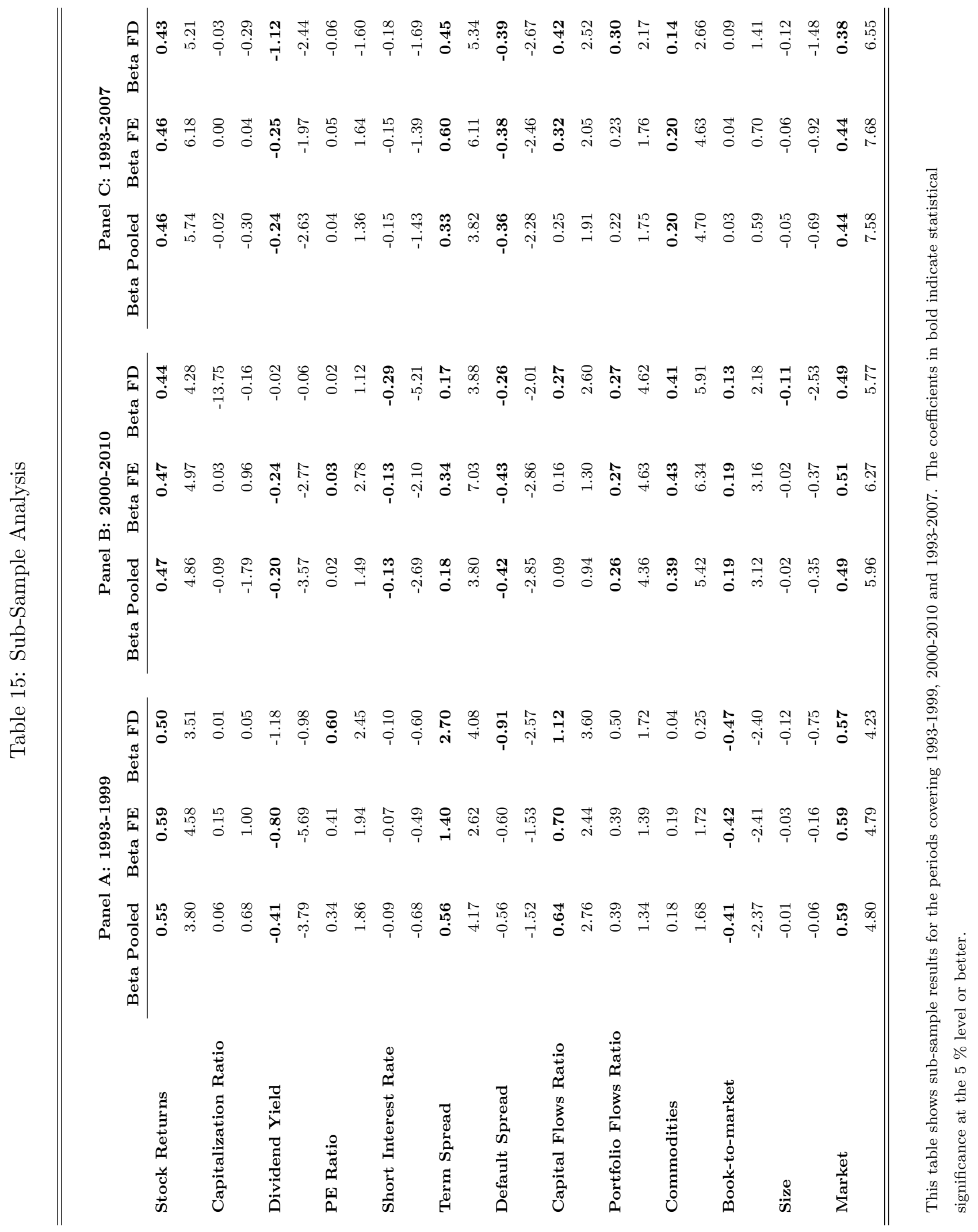




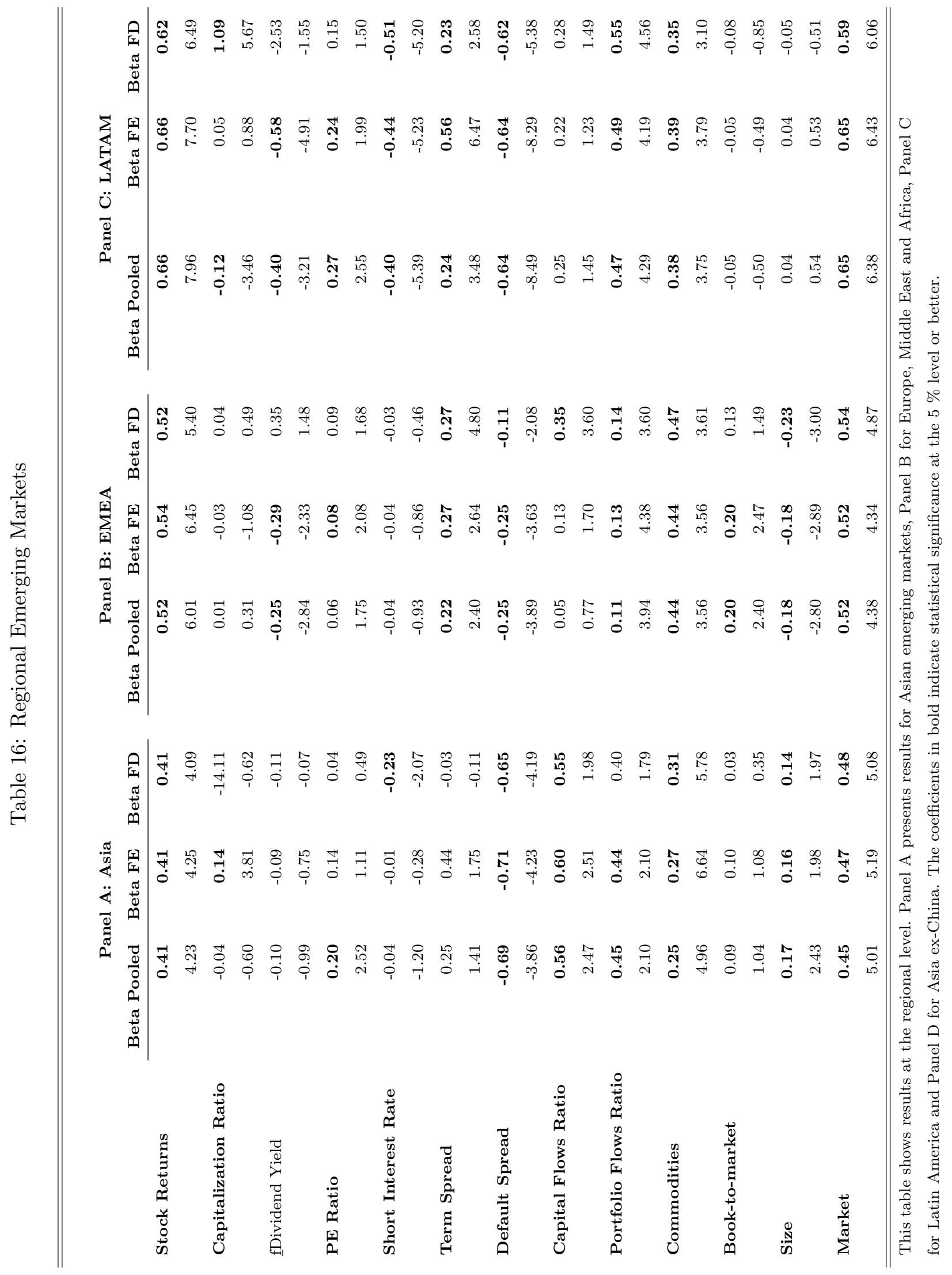


Regional Emerging Markets (Continued)

\begin{tabular}{|c|c|c|c|}
\hline & \multicolumn{3}{|c|}{ Panel D: Asia ex-China } \\
\hline & Beta Pooled & Beta FE & Beta FD \\
\hline \multirow[t]{2}{*}{ Stock Returns } & 0.38 & 0.38 & 0.35 \\
\hline & 3.86 & 3.91 & 3.54 \\
\hline \multirow[t]{2}{*}{ Capitalization Ratio } & 0.02 & 0.12 & -14.34 \\
\hline & 0.88 & 3.38 & -0.56 \\
\hline \multirow[t]{2}{*}{ Dividend Yield } & -0.14 & -0.13 & 0.20 \\
\hline & -1.46 & -1.12 & 0.25 \\
\hline \multirow[t]{2}{*}{ PE Ratio } & 0.24 & 0.26 & 0.14 \\
\hline & 4.72 & 4.86 & 1.42 \\
\hline \multirow[t]{2}{*}{ Short Interest Rate } & -0.01 & -0.01 & -0.24 \\
\hline & -0.52 & -0.43 & -2.10 \\
\hline \multirow[t]{2}{*}{ Term Spread } & 0.25 & 0.44 & -0.03 \\
\hline & 1.41 & 1.75 & -0.11 \\
\hline \multirow[t]{2}{*}{ Default Spread } & -0.79 & -0.79 & -0.74 \\
\hline & -4.17 & -4.12 & -4.65 \\
\hline \multirow[t]{2}{*}{ Capital Flows Ratio } & 0.56 & 0.60 & 0.55 \\
\hline & 2.47 & 2.51 & 1.98 \\
\hline \multirow[t]{2}{*}{ Portfolio Flows Ratio } & 0.45 & 0.44 & 0.40 \\
\hline & 2.10 & 2.10 & 1.79 \\
\hline \multirow[t]{2}{*}{ Commodities } & 0.29 & 0.30 & 0.35 \\
\hline & 7.83 & 7.87 & 7.33 \\
\hline \multirow[t]{2}{*}{ Book-to-market } & 0.05 & 0.05 & -0.02 \\
\hline & 0.57 & 0.56 & -0.23 \\
\hline \multirow[t]{2}{*}{ Size } & 0.22 & 0.22 & 0.19 \\
\hline & 3.66 & 3.60 & 3.55 \\
\hline \multirow[t]{2}{*}{ Market } & 0.47 & 0.48 & 0.48 \\
\hline & 4.85 & 4.88 & 4.68 \\
\hline
\end{tabular}




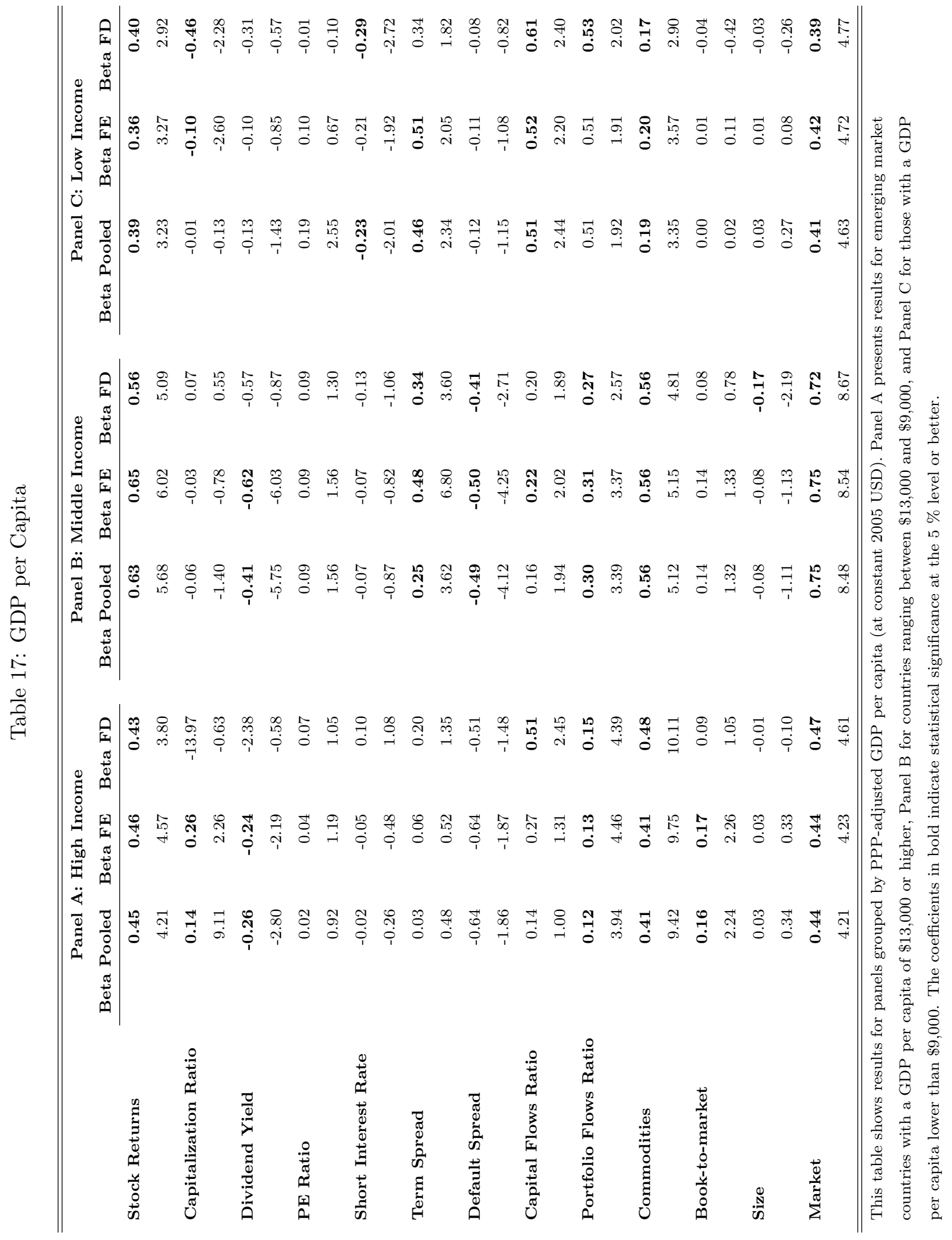




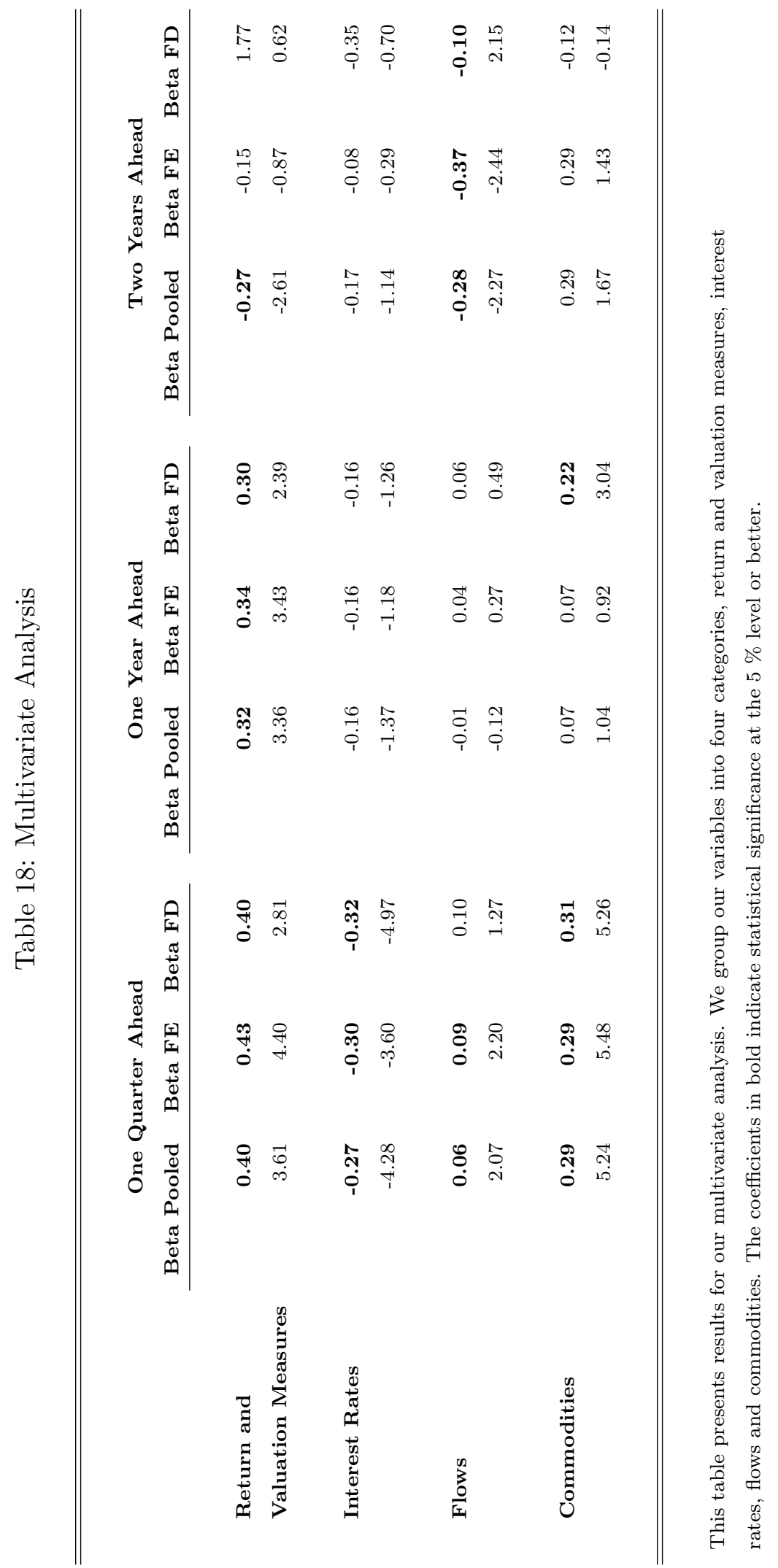


Table 19: Cross-Validation

\begin{tabular}{|c|c|c|c|c|c|c|c|c|c|}
\hline & \multicolumn{3}{|c|}{ One Quarter Ahead } & \multicolumn{3}{|c|}{ One Year Ahead } & \multicolumn{3}{|c|}{ Two Years Ahead } \\
\hline & Pooled & FE & FD & Pooled & FE & FD & Pooled & FE & FD \\
\hline Stock Returns & 0.51 & 0.52 & 0.49 & 0.63 & 0.67 & 0.63 & 0.37 & 0.44 & 0.40 \\
\hline Stdv. & 0.03 & 0.03 & 0.03 & 0.04 & 0.04 & 0.05 & 0.03 & 0.03 & 0.05 \\
\hline No. Sig. & 20 & 20 & 20 & 20 & 20 & 20 & 20 & 20 & 20 \\
\hline Capitalization Ratio & -0.04 & 0.02 & 0.48 & -0.08 & -0.13 & 0.30 & -0.07 & -0.15 & 3.12 \\
\hline Stdv. & 0.03 & 0.06 & 0.94 & 0.03 & 0.05 & 0.71 & 0.03 & 0.10 & 10.80 \\
\hline No. Sig. & 0 & 2 & 0 & 4 & 20 & 0 & 1 & 2 & 0 \\
\hline Dividend Yield & -0.27 & -0.30 & -0.34 & -0.07 & -0.06 & 0.27 & -0.02 & 0.02 & 1.35 \\
\hline Stdv. & 0.03 & 0.04 & 0.20 & 0.02 & 0.03 & 2.13 & 0.02 & 0.04 & 1.08 \\
\hline No. Sig. & 20 & 20 & 0 & 0 & 0 & 0 & 0 & 0 & 0 \\
\hline PE Ratio & 0.05 & 0.06 & 0.06 & -0.01 & 0.01 & -0.03 & 0.05 & 0.07 & 0.01 \\
\hline Stdv. & 0.01 & 0.01 & 0.01 & 0.01 & 0.01 & 0.01 & 0.02 & 0.02 & 0.02 \\
\hline No. Sig. & 0 & 4 & 0 & 0 & 0 & 0 & 1 & 17 & 0 \\
\hline Short Interest Rate & -0.11 & -0.09 & -0.12 & -0.01 & 0.03 & -0.05 & 0.01 & 0.01 & -0.12 \\
\hline Stdv. & 0.03 & 0.03 & 0.03 & 0.05 & 0.05 & 0.05 & 0.03 & 0.04 & 0.05 \\
\hline No. Sig. & 0 & 0 & 1 & 0 & 0 & 0 & 0 & 0 & 2 \\
\hline Term Spread & 0.29 & 0.48 & 0.34 & 0.23 & 0.50 & 0.26 & 0.11 & 0.27 & 0.05 \\
\hline Stdv. & 0.03 & 0.06 & 0.04 & 0.04 & 0.12 & 0.05 & 0.05 & 0.10 & 0.05 \\
\hline No. Sig. & 20 & 20 & 20 & 19 & 19 & 6 & 4 & 4 & 0 \\
\hline Default Spread & -0.42 & -0.44 & -0.36 & -0.42 & -0.53 & -0.30 & -0.17 & -0.33 & 0.36 \\
\hline Stdv. & 0.05 & 0.05 & 0.05 & 0.04 & 0.03 & 0.08 & 0.03 & 0.03 & 0.11 \\
\hline No. Sig. & 20 & 20 & 20 & 20 & 20 & 4 & 18 & 20 & 12 \\
\hline Capital Flows & 0.26 & 0.33 & 0.44 & -0.05 & -0.05 & 0.11 & -0.19 & -0.29 & -0.13 \\
\hline Stdv. & 0.03 & 0.04 & 0.05 & 0.02 & 0.03 & 0.05 & 0.02 & 0.03 & 0.05 \\
\hline No. Sig. & 20 & 20 & 20 & 2 & 0 & 2 & 20 & 20 & 5 \\
\hline Portfolio Flows & 0.30 & 0.30 & 0.31 & 0.10 & 0.10 & 0.12 & -0.04 & -0.05 & -0.01 \\
\hline Stdv. & 0.03 & 0.04 & 0.03 & 0.03 & 0.03 & 0.04 & 0.02 & 0.03 & 0.04 \\
\hline No. Sig. & 20 & 20 & 20 & 0 & 0 & 3 & 0 & 0 & 0 \\
\hline
\end{tabular}

This table presents results for our cross-validation analysis. For each variable we report the average estimate, its standard deviation and the number of times, out of the twenty random draws, that the coefficient is statistically significant. 
Cross-Validation (Continued)

\begin{tabular}{|c|c|c|c|c|c|c|c|c|c|}
\hline & \multicolumn{3}{|c|}{ One Quarter Ahead } & \multicolumn{3}{|c|}{ One Year Ahead } & \multicolumn{3}{|c|}{ Two Years Ahead } \\
\hline & Pooled & FE & FD & Pooled & FE & FD & Pooled & FE & FD \\
\hline Debt securities & 0.13 & 0.14 & 0.19 & -0.02 & -0.04 & 0.07 & -0.09 & -0.15 & 0.03 \\
\hline Stdv. & 0.03 & 0.03 & 0.03 & 0.04 & 0.04 & 0.05 & 0.03 & 0.03 & 0.07 \\
\hline No. Sig. & 16 & 18 & 20 & 0 & 0 & 1 & 6 & 7 & 0 \\
\hline Direct Inv. flows & 0.04 & 0.08 & 0.13 & 0.02 & 0.11 & 0.10 & -0.04 & 0.07 & 0.01 \\
\hline Stdv. & 0.02 & 0.03 & 0.03 & 0.01 & 0.02 & 0.03 & 0.02 & 0.04 & 0.05 \\
\hline No. Sig. & 0 & 2 & 11 & 0 & 7 & 4 & 2 & 0 & 0 \\
\hline Equity securities & 0.16 & 0.16 & 0.07 & 0.12 & 0.15 & -0.06 & 0.09 & 0.11 & -0.29 \\
\hline Stdv. & 0.03 & 0.03 & 0.03 & 0.03 & 0.04 & 0.03 & 0.04 & 0.06 & 0.08 \\
\hline No. Sig. & 15 & 15 & 0 & 4 & 11 & 0 & 0 & 1 & 0 \\
\hline Size & -0.01 & -0.03 & -0.08 & 0.39 & 0.35 & 0.37 & 0.47 & 0.45 & 0.51 \\
\hline Stdv. & 0.02 & 0.02 & 0.03 & 0.04 & 0.04 & 0.05 & 0.03 & 0.03 & 0.03 \\
\hline No. Sig. & 0 & 0 & 0 & 20 & 20 & 20 & 20 & 20 & 20 \\
\hline HML & 0.09 & 0.10 & 0.05 & 0.05 & 0.08 & -0.05 & -0.05 & -0.04 & -0.37 \\
\hline Stdv. & 0.02 & 0.02 & 0.02 & 0.01 & 0.01 & 0.03 & 0.02 & 0.02 & 0.05 \\
\hline No. Sig. & 3 & 3 & 0 & 1 & 3 & 0 & 0 & 0 & 20 \\
\hline Market & 0.11 & 0.10 & -0.99 & -0.08 & -0.09 & -1.44 & -0.16 & -0.17 & -1.54 \\
\hline Stdv. & 0.02 & 0.02 & 0.18 & 0.02 & 0.03 & 0.64 & 0.02 & 0.03 & 0.74 \\
\hline No. Sig. & 12 & 9 & 20 & 2 & 3 & 3 & 20 & 20 & 0 \\
\hline Commodities & 0.38 & 0.39 & 0.40 & 0.22 & 0.27 & 0.33 & 0.15 & 0.21 & 0.36 \\
\hline Stdv. & 0.02 & 0.02 & 0.02 & 0.03 & 0.03 & 0.03 & 0.02 & 0.02 & 0.03 \\
\hline No. Sig. & 20 & 20 & 20 & 20 & 20 & 20 & 14 & 20 & 20 \\
\hline S\&P Agriculture & 0.35 & 0.35 & 0.39 & 0.18 & 0.21 & 0.35 & 0.01 & 0.04 & 0.38 \\
\hline Stdv. & 0.02 & 0.02 & 0.02 & 0.03 & 0.03 & 0.02 & 0.02 & 0.02 & 0.05 \\
\hline No. Sig. & 20 & 20 & 20 & 17 & 20 & 20 & 0 & 0 & 20 \\
\hline S\&P Energy & 0.29 & 0.30 & 0.30 & 0.17 & 0.22 & 0.25 & 0.11 & 0.15 & 0.22 \\
\hline Stdv. & 0.02 & 0.02 & 0.02 & 0.02 & 0.02 & 0.02 & 0.02 & 0.02 & 0.03 \\
\hline No. Sig. & 20 & 20 & 20 & 19 & 20 & 20 & 8 & 20 & 20 \\
\hline S\&P Livestock & 0.15 & 0.16 & 0.14 & 0.21 & 0.24 & 0.19 & 0.06 & 0.10 & 0.01 \\
\hline Stdv. & 0.03 & 0.03 & 0.03 & 0.03 & 0.03 & 0.03 & 0.03 & 0.03 & 0.03 \\
\hline No. Sig. & 18 & 20 & 12 & 20 & 20 & 19 & 0 & 0 & 0 \\
\hline S\&P MetalS & 0.38 & 0.37 & 0.47 & 0.30 & 0.30 & 0.59 & 0.20 & 0.21 & 0.83 \\
\hline Stdv. & 0.02 & 0.02 & 0.02 & 0.02 & 0.02 & 0.05 & 0.02 & 0.02 & 0.11 \\
\hline No. Sig. & 20 & 20 & 20 & 20 & 20 & 20 & 20 & 20 & 20 \\
\hline
\end{tabular}

